\section{The role of resident monocytes and vascular pericytes in the stem cell niche and regenerative medicine}

\author{
Antonin Bukovsky \\ The Institute of Biotechnology, Academy \\ of Sciences of the Czech Republic, \\ Prague, Czech Republic
}

\section{Abstract}

The perivascular tissue-specific stem cell niche (SCN) determines nuclear reprogramming of multipotent stem cells into particular cell types in distinct tissues in vivo. It represents a morphostatic (homeostatic) mechanism executed by the so-called tissue control system (TCS), which is associated with postcapillary venules and consists of vascular pericytes regulated by the autonomic nervous system and of resident perivascular monocytederived cells. Tissue morphostasis executed by the TCS is a complex procedure consisting of three processes: i) Stem cell and tissue renewal by asymmetric division of stem cells, ii) Preservation of tissue cells in a properly differentiated (functional) state, and iii) Maintenance of tissue quantity. The TCSmediated functional preservation of tissuespecific cells is established during the morphogenetic critical developmental period, such as developmental immune adaptation, as a stop effect at the level of resident self-renewing tissue monocyte-derived cells (MDC), and its function declines with advancing age. The functional stop effect differs between the tissues, and an inhibition or acceleration of tissue differentiation during the critical developmental period can result in persistent functional immaturity or premature tissue aging. In addition, a retardation of tissue development can cause an earlier failure of that tissue function, like a premature ovarian failure. A promising approach in regenerative medicine is a chemical approach, such as the combination of sex steroids stimulating growth of endogenous stem cells for neuronal, vascular, and cardiac repair. Sex steroid combinations and doses for clinical applications are suggested. Regenerative medicine may be more successful in acute/traumatic disorders with intact morphostatic SCN compared to the chronic and degenerative diseases caused by an altered SCN. If we attain the capacity to repair the function of altered SCN and the tissue-specific stop effect by trascriptional therapy, we may be able to provide novel treatments for early postnatal tissue disorders, improve regenerative medicine, and delay aging.

\section{Introduction}

The perivascular tissue-specific stem cell niche (SCN) is essential for preservation and differentiation of endogenous stem cells. The composition/effectors, function, tissue-specific differences, and alterations with age of SCNs are still poorly understood. The goal of regenerative medicine is to replace altered or lost functional cells in certain tissue with exogenous stem cells, such as embryonic stem cells (ESC) or adult-derived induced pluripotent stem cells (iPSCs) capable of differentiation into tissue-specific functional cells. Such an approach has, however, a number of obstacles, such as ethical concerns, immune responses after administration, the potential of teratoma formation, the inability of stem cells to regenerate, cell cycle arrest, differentiation into functional tissues, and apoptosis. ${ }^{1-3}$ In addition, most attempts to establish ESC from large mammals have not been success$\mathrm{ful}^{4}$ and human iPSCs exhibit teratoma formations when tested in immuno-compromised animals. ${ }^{5}$ Recent study also indicates that iPSCs retain a distinct genome methylation memory of their past, which can reduce their therapeutic utility. ${ }^{6}$

An alternative approach is to induce a patient's own pluripotent stem cells to differentiate in situ. This may be successful in acute/traumatic disorders with preserved appropriate perivascular tissue-specific SCN required for the maintenance of stem cells and their differentiation into the functional state and preservation in a such condition. There is also a possibility to utilize transdifferentiation of autologous cells, a process transforming non-stem cells into different types of cells. For instance differentiated exocrine pancreatic cells can be converted into hepatocytes by treatment with a synthetic glucocorticoid, dexamethasone, ${ }^{7}$ pancreatic beta-cells can differentiate from hepatocytes with gene transfer by recombinant adenoviruses $^{8}$ or from adult exocrine pancreatic cells with epidermal growth factor (EGF) and leukemia inhibitory factor, ${ }^{9}$ and differentiated vascular smooth muscle cells can be converted into neuronal type cells by sex steroid combinations ${ }^{10}$ (see below). Another possibility is to change a differentiation path of committed intrinsic stem cells outside of their already established differentiation course. For instance muscle progenitor cells, committed to the myogenic pathway, transdifferentiate to neurons, following their inoculation into the developing brain of newborn mice. ${ }^{11}$ This indicates that distinct SCN can by itself convert (reprogram) muscle committed stem cells into a distinct path of their differentiation.

Such approaches eliminate most of the hurdles listed above but don't address concerns
Correspondence: Antonin Bukovsky, Institute of Biotechnology, Academy of Sciences of the Czech Republic, Prague, Czech Republic.

E-mail: a_buko@comcast.net

Key words: tissue morphostasis, stem cell niche, tissue renewal, regenerative medicine, chemical approach.

Received for publication: 3 August 2011. Accepted for publication: 4 October 2011.

This work is licensed under a Creative Commons Attribution NonCommercial 3.0 License (CC BYNC 3.0).

(C) Copyright A. Bukovsky, 2011

Licensee PAGEPress, Italy

Stem Cell Studies 2011; 1:e20

doi:10.4081/scs.2011.e20

about the efficiency of stem cell differentiation in enhancing the return of normal tissue function. ${ }^{1}$ Long lasting disorders may be associated with an altered perivascular tissue-specific SCN causing persisting tissue dysfunction, and degenerative diseases may be caused by an altered SCN stimulating apoptotic degeneration of functional tissue cells. In other words, improper tissue function is maintained by improper tissue-specific SCN, and stimulation of stem cells toward differentiation will thereby cause their dysfunction or degeneration.

Attempts to improve altered tissue function by stem cells differentiation into functional cells may not be successful unless we will be able to manage repair. ${ }^{12}$ Animal experiments dealing with disorders of pancreas, heart, liver, and nervous system have been somewhat successful compared to the human clinical trials, ${ }^{2}$ possibly due to the preservation of the proper perivascular tissue-specific SCN after induction of a disorder in the animals.

\section{What is the perivascular \\ tissue-specific stem cell niche?}

Mesenchymal stem cells from various tissues reside in a perivascular location and these can be identified as pericytes that function as mural cells in microvessels. ${ }^{13}$ Pericytes secrete large quantities of bioactive trophic factors stimulating tissue intrinsic progenitor cells. $^{13}$ Beside their trophic function in perivascular tissue-specific SCN, some pericytes have also been shown to exhibit mesenchymal stem cell properties and are capable of nuclear reprogramming into distinct cell types such as testicular Leydig cells, ${ }^{14}$ cardiomyocytes, ${ }^{15}$ cartilage and bone,${ }^{16}$ and neural and neuronal type cells. ${ }^{10}$ Hence pericytes display a dual role in the perivascular tissuespecific SCN: exhibiting a trophic function for 
intrinsic progenitor cells and possessing the capacity to reprogramming into tissue intrinsic progenitor cells when such cells are required. Pericytes show a similar gene expression as neural cells, and pericytes and neuronal cells originate from the neural crest, ${ }^{17}$ but from different germ layers. The activity of perivascular tissue-specific SCN is modulated by autonomic innervation (AI), ${ }^{18}$ which regulates pericyte numbers and their function. ${ }^{19,20}$

Another essential component of the perivascular SCN are monocyte-derived cells (MDC) associated with the microvasculature. It has been shown that depletion of MDC in one testis of adult rats selectively abolishes the differentiation of Leydig cells from mesenchymal precursors, ${ }^{21}$ such as vascular pericytes. ${ }^{14}$ Recent findings indicate that $\mathrm{CD} 14^{+}$ primitive MDC (pMDC) in the circulation are involved in a variety of physiologic functions in addition to innate and acquired immune responses, such as repair and regeneration of tissues. ${ }^{22} \mathrm{CD} 14^{+}$pMDC also stimulate the proliferation of tissue-intrinsic progenitor cells, and MDC regulate their preservation in the tissue-specific functional state. ${ }^{12}$ Therefore, the MDC have multiple roles in the perivascular tissue-specific SCN. They stimulate division of intrinsic progenitor cells, participate in the stimulation of their differentiation, and preserve differentiated cells in the tissue-specific functional state.

It appears that the perivascular tissue-specific SCN is a relatively straight-forward structure, consisting of pericytes regulated by $\mathrm{AI}$ and perivascular $\mathrm{CD} 14^{+} \mathrm{pMDC}$. It is associated with microvasculature throughout the body and influences tissue intrinsic progenitor cells required for tissue regeneration and repair. This basic tissue control unit requires incorporation into a more complex system called the tissue control system (TCS), exhibiting marked diversity among various tissues. Tissues differ on the extent of cellular differentiation between stem cells and apoptosis. To function properly, stage of cellular differentiation of some tissues ceases relatively early (brain, pancreas, skeletal muscle). Other reach a moderate stage of differentiation enabled by intraepithelial T cells (gut epithelium), and some tissues differentiate into cornified (apoptotic) superficial cells by binding immunoglobulins (stratified epithelium of epidermis and uterine ectocervix). Interruption of tissue cell differentiation before attaining a functional state causes tissue dysfunction due to the immaturity. Differentiation of tissue cells more than required causes autoimmune and degenerative diseases (see below).

\section{The tissue control system}

In 1922, Alexis Carrel showed that leukocyte extracts, like embryonic tissue extracts, possessed the power to increase the rate of multiplication of fibroblasts in vitro. ${ }^{23}$ In 1963, R. Geoffrey Burwell suggested that immune system plays an important role in tissue morphostasis ${ }^{24}$ and in 1980, Isaiah J. Fidler stated that participation in host immune responses is only one of many functions of lymphocytes, and that lymphocytes may function as trephocytes, regulating the growth of various organs.

Our studies, starting in the late 1970 s, ${ }^{25-27}$ expanded the concept of a wider role of immune system-related cells and vascular pericytes (the so called TCS), in the regulation of differentiation of tissue specific cells. ${ }^{28}$ The TCS theory was further expanded by a comparison of the rat skeletal muscle development and regeneration, ${ }^{29}$ and refined when the role of $\mathrm{AI}$ in the regulation of quantitative aspects in tissues was discovered. ${ }^{30}$ The theory was advanced further by morphostatic studies of TCS in the ovary, ${ }^{31-36}$ placenta, ${ }^{37}$ stratified squamous epithelium, ${ }^{38,39}$ and cancer. ${ }^{40-42}$ In addition, we investigated a role of the developmental immune adaptation in tissue longevity ${ }^{43-46}$ and a role of $\mathrm{CD}_{14}{ }^{+} \mathrm{pMDC}$ and $\mathrm{T}$ cells in the induction of asymmetric division of somatic stem cells. ${ }^{47-49}$ Complex aspects of immune physiology in tissue regeneration and aging, tumor growth, and regenerative medicine were analyzed more recently. ${ }^{10,12,50-53}$

The developmental adaptation is a period during fetal life, during which a character of function of various tissues during further life is epigenetically programmed. Many of the adult-onset morbidities are accompanied by changes in the expression of genes regulating, among other things, metabolic processes, apoptosis, and cellular signaling. For instance fetal undernutrition or environmental pollutants are associated with an increased susceptibility to several adult onset metabolic disorders, including cardiovascular disease, insulin resistance, and obesity. ${ }^{54,55}$

TCS-mediated tissue morphostasis is a complex process consisting of primarily three processes i) tissue renewal from stem cells, ii) maintenance of tissue quantity, and iii) preservation of cells in a proper (functional) state of differentiation, which differs among tissues. Study of the immune system after partial organ resection has shown that the lymphatic system is specifically activated. Lymphocytes primed by a partial hepatectomy initiate and maintain the growth of liver until the original size of the organs is complete. Transfer experiments show that these lymphocytes stimulate the growth of liver in intact recipients as well. ${ }^{56}$

Therefore, a mechanism initiates and maintains a priming of lymphocytes after partial hepatectomy resulting in the stimulation of liver regeneration. This mechanism is silenced when the original size of the liver is reached. It appears that the size of each tissue is regulated by AI, since elimination of certain areas of the cephalic neural crest in stage 9 or 10 chick embryos markedly reduced the size of the thymus gland. ${ }^{57,58}$ Disruption of neural crest cells can result in a spectrum of outflow tract defects, including decreased total cell number (hypoplasia) in the liver. ${ }^{59}$

Recently, Sprent and Cho indicated that, for $\mathrm{T}$ cells, a limited degree of autoreactivity is beneficial for the immune system. ${ }^{60}$ In our opinion, such limited degree of interaction of the immune system with self is represented by a support of differentiation of unaltered self tissue cells. ${ }^{39}$ Therefore, it is assumed that the immune system has a dual function: i) eliminates non-self cells and substances, including viral and bacterial infections and malignant cells, ${ }^{61}$ by immune surveillance and ii) actively promotes differentiation of self cells by an immune maintenance of self, i.e. immune system involvement in morphostasis of tissues. ${ }^{12}$

Monocyte-derived cells are present in virtually all tissues, and T cells are present in a variety of normal epithelial tissues, including the intestinal tract, respiratory tract, genitourinary tract epithelium, and the skin..$^{6}$ Intraepithelial lymphocytes (IEL) are T-cell antigen receptor (TCR) alpha/beta of thymic origin and gamma/delta mostly of extrathymic origin..$^{63}$ It is unclear which of these two distinct $\mathrm{T}$ cell populations plays a specific role in immune surveillance and tissue morphostasis. Microbial deprivation in germ-free mice preferentially influences the intestinal intraepithelial alpha/beta $\mathrm{T}$ cell population to decrease and become noncytolytic but has a little effect on the pool size or characteristics of intestinal intraepithelial gamma/delta T cells. ${ }^{64}$ This suggests that the alpha/beta $\mathrm{T}$ cell population is involved in immune surveillance and gamma/delta $\mathrm{T}$ cells are agents of immune morphostasis in tissues.

Tissue control system consists of distant regulatory mechanisms, such as autonomic innervation system and lymphoid tissues producing $\mathrm{T}$ cells and autoantibodies, and local Tissue control units regulating regeneration and differentiation of particular tissue. In other words, the local Tissue control units are influenced by distant regulatory mechanisms of the TCS.

\section{The basic tissue control unit}

The Tissue Control Unit (TCU) is proximally associated with postcapillary venules and consists of vascular pericytes innervated by $\mathrm{AI}$ and of perivascular $\mathrm{CD} 14^{+}$pMDC. $^{12}$ The $\mathrm{AI}$ accompanies vascular pericytes in most tissues but is absent in neovascularization of the ovarian corpus luteum (CL) ${ }^{65}$ and invasive cancer, including tumor vessels. ${ }^{66}$ Lack of vascular innervation in these tissues is accompanied by the release of substantial amounts of 
Thy-1 differentiation protein, a morpho-regulatory molecule associated with cell differentiation, ${ }^{31,67}$ from vascular pericytes. ${ }^{42}$ On the other hand, in innervated structures, such as primordial ovarian follicles, ${ }^{65}$ Thy- 1 release is enabled only in growing structures and inhibited in resting ones. ${ }^{42}$ These observations suggest that Thy-1 release is inversely correlated to the inhibitory presence of innervation ( $\mathrm{AI}$ $/ \mathrm{AI}^{+}$in Figure 1A). In other words, resting ovarian follicles are ready to grow when the AI stops inhibiting activity of their vascular pericytes. ${ }^{42}$ Thus the number of primordial follicles entering a growing stage is determined by the AI. The activity of the TCU is enabled by a lack of AI inhibition and initiated by a signal (blue arched arrow, Figure 1A) from tissue specific cells, e.g. epithelial stem cells (SC in Figure 1A), toward perivascular CD14+ ${ }^{+}$MDC (pM, Figure 1A) to stimulate stem cell division. Prior to stimulation of division, CD14 ${ }^{+}$pMDC may interact with pericytes (yellow up-down arrow) since the activity of $\mathrm{CD} 14^{+}$pMDC is regulated by tissue fibroblasts/pericytes. ${ }^{68,69}$ Next, the $\mathrm{CD}_{14}{ }^{+}$pMDC stimulate (red sun symbol) division of tissue intrinsic stem cells by release of CD14 lipopolysaccharide receptors $^{70}$ among stem cells. ${ }^{32,42}$

\section{Monocyte-derived cells}

During regeneration, tissue MDC produce cytokines and chemotactic factors attracting fibroblasts and endothelial cells. MDC often activate them to produce additional mediators stimulating angiogenesis and cell maturation. ${ }^{71-78}$ Tissue MDC secrete numerous growth factors and cytokines stimulating tissue regeneration, reconstruction, and wound healing. ${ }^{72,76,79}$ These include TNFa, TNF-like weak inducer of apoptosis (TWEAK), lymphotoxin beta (LTb), members of the interleukin (IL)-6like family including IL-6, oncostatin $\mathrm{M}$ and interferon gamma (IFNc). Invading MDC play a major role in the liver progenitor cell response to chronic liver injury, and knockout studies suggest that a combination of cytokines is important for this process. ${ }^{80}$

Figure 1B shows CD14+ ${ }^{+}$pMDC (brown color) in the lamina propria (lp), entering (arrows) through the basement membrane (white dotted line), the basal epithelial layer (b; epithelial stem cells = stage 1 of differentiation) of the stratified squamous epithelium of uterine ectocervix. The association of $\mathrm{CD} 14^{+}$ pMDC with stem cells (yellow arrowhead) causes division of stem cells (red arrowheads). One of the two postmitotic cell daughters passes the basal/parabasal interface (black dotted line) and enters (upper red arrowhead and white arrowheads) parabasal epithelial layer (pb), representing an early epithelial differentiation (stage 2). Replication of the stem cell daughter (SCD, Figure 1A) is important for a maintenance of the tissue stem cell content.
Commitment toward differentiation (differentiating cell daughter - DCD, Figure 1A) may require physical involvement of $\mathrm{T}$ cell ( $\mathrm{T}$, Figure 1A). Tissues lacking T cells, may utilize extrinsic mechanism of spindle orientation during mitosis with intrinsic mechanism of asymmetric distribution of differentiation promoting proteins. ${ }^{81}$ The inset in Figure 1B shows Ki $67^{+}$postmitotic cells (arrowheads) in the lower parabasal layer; arrows indicate numerous Ki67+ cells in the adjacent lamina propria. Note a lack of Ki67+ cells in the basal layer containing mitotically active stem cells. This indicates that Ki67+ cells represent postmitotic cells originating by asymmetric division of Ki67 negative stem cells in the basal layer. Accumulation of $\mathrm{CD}_{14}^{+}$pMDC among

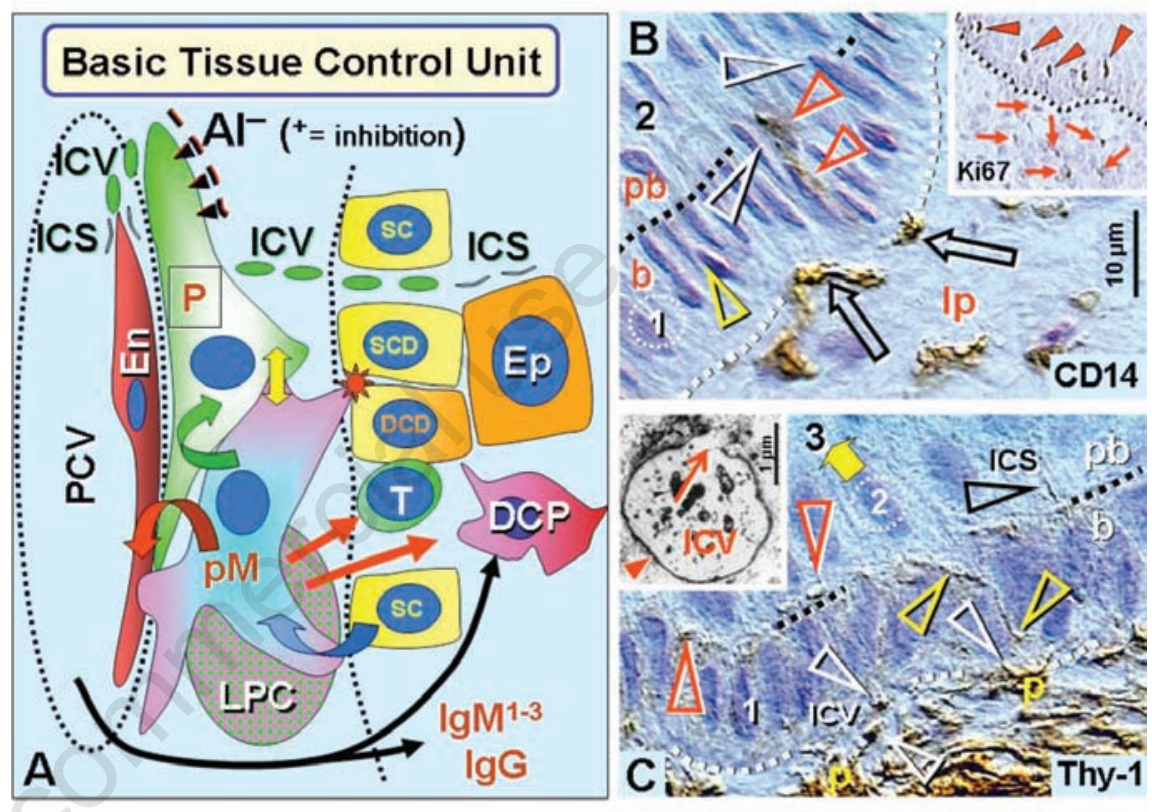

Figure 1. Basic Tissue Control Unit (TCU). CD14 ${ }^{+}$pMDC and Thy- $1^{+}$pericyte interaction with endothelial cells and stem and parabasal cells in the squamous cornified epithelium. A) Basic TCU consists of $\mathrm{CD}_{14}{ }^{+}$primitive monocyte-derived cells (MDC, $\mathrm{pM}$ in panel A) stimulating cell division (see panel $B$ with inset) and of vascular pericytes (P) secreting Thy-1 $1^{+}$intercellular vesicles (ICV) collapsing into intercellular spikes (ICS) after reaching target cells (see panel $\mathrm{C}$ with inset). The primitive MDC and vascular pericytes interact themselves (yellow up-down arrow) and influence stem and differentiating epithelial (Ep) and endothelial cells (En). The activity of pericytes and TCU can be inhibited by $\mathrm{AI}\left(\mathrm{AI}^{+}\right)$. Interaction of primitive $\mathrm{MDC}$ and pericytes with endothelial cells may stimulate homing of dendritic cell precursors (DCP), which differentiate within epithelium into mature dendritic cells, and homing of intraepithelial T cells (T). In some tissues DCP and T cells originate (red arrows) from the self renewing lamina propria cryptopatches (LPC). The differentiation of epithelial cells may be enhanced by autoreactive IgMs (IgM ${ }^{1-3}$ ) and IgG. B) CD14 ${ }^{+}$MDC invade basal (b) epithelial layer (arrows), and associate (yellow arrowhead) with dividing stem cells (red arrowheads). The differentiation-committed postmitotic cells (white arrowheads) enter the parabasal (pb) layer and express Ki-67 (arrowheads, inset). Arrows in inset indicate Ki67+ cells in the lamina propria. C) Thy- $1^{+}$vascular pericytes ( $p$ ) adjacent to the epithelium basement membrane (white dotted line) secrete Thy $-1^{+}$large intercellular vesicles (ICV, white arrowheads, 2 micrometers in size) which migrate among basal epithelial cells (yellow arrowheads) above (red arrowheads) the basal/ parabasal interface (b/pb, black dotted line), where they collapse into Thy-1 ${ }^{+}$intercellular spikes (ICS, black arrowhead). Inset shows in immunoelectron microscopy ICV with the surface Thy-1 expression (arrowhead) and a release of the vesicle content (arrow). Yellow arrow indicates cellular transition from stage 2 to stage 3 of the epithelial cell differentiation. Numbers in panels $B$ and $C$ indicate stage of epithelial cell differentiation - see Figure 2 for details. Bar in panel B - for B and C. Adapted from $^{39},{ }^{\odot}$ Antonin Bukovsky; inset in $\mathrm{C}$ from $^{91}$ with permission, ${ }^{\odot}$ Roma: Antonio Delfino Editore. 
ed by the interaction of CD14+ pMDC with pericytes in TCU (green arched arrow, Figure 1A). The pericytes release intercellular Thy-1+ ${ }^{+}$vesicles (ICV) migrating by chemotaxis through the basement membrane and among basal (stem) cells, and collapsing into intercellular spikes (ICS, Figure 1A) after reaching target cells. ${ }^{28,39} \mathrm{~A}$ similar event is executed in the differentiation of endothelial cells. ${ }^{42}$

Most of the molecules involved in the TCS pathway belong to the immunoglobulin (Ig) superfamily. It has been suggested that the function of Ig-related molecules in tissue interactions is more primitive than their involvement in the immune system and the immune functions evolved from sets of molecules mediating tissue interactions. ${ }^{89}$ One of them, Thy-1 differentiation protein, consists of a single Ig domain, and represents the most primitive and member of the Ig-superfamily. Ig-related molecules have diverse functions, but their common denominator is cell surface recognition..$^{90}$ The only known function of Thy1 differentiation protein and other Ig-related molecules is to mediate recognition, due in part to the differentiated state of the cells. Recognition requires that the correct ligand and receptor are expressed on the appropriate cells at the right time. ${ }^{89}$

Staining for Thy-1 differentiation protein (Figure 1C) shows pericytes (p) associated with microvasculature adjacent to the basement membrane (white dotted line). The pericytes secrete intercellular vesicles (ICV, white arrowheads), which migrate though the basement membrane among basal epithelial cells (Thy-1 ICV route, yellow arrowheads) above (red arrowheads) the b/pb interface (black dotted lines). After reaching the postmitotic parabasal cells, the Thy-1+ ICV collapse into empty intercellular spikes (ICS, black arrowhead; see also Figure 1A). Thus, targets for Thy-1 vesicles are parabasal cells adjacent to the $\mathrm{b} / \mathrm{pb}$ interface, i.e., epithelial cells expressing Ki67 and entering differentiation (yellow arrow, stage 2 to stage 3 transition). The origin of intercellular vesicles from pericytes is indicated by Thy- 1 staining of both structures.

The intercellular Thy-1 vesicles have been shown by immunoelectron microscopy to exhibit Thy-1 surface expression and contain a substance lacking Thy-1 staining ${ }^{91}$ (shown in inset, Figure 1C, where the arrowhead shows Thy-1+ ICV surface and arrow indicates ICV opening and release of the content). In this way growth factors and cytokines released by pericytes ${ }^{17 ; 83-88}$ which stimulate differentiation of certain epithelial cells are delivered and released in a close vicinity of the target cells.

\section{Targeted delivery of differentiation promoting substances}

The Thy-1 ICV represents an elaborate paracrine mechanism via Thy-1 recognition at the cell surface. ${ }^{39}$ Certain growth factors (vesicle content) are delivered to type/stage specific target cells expressing the receptor for Thy1 ligand (targeted delivery). The receptor for Thy-1 has not yet been identified, but the possibility is that the differentiating $\mathrm{Ki} 67^{+}$cells are targets of Thy-1+ ICV. Also, there is a lack of expression of major histocompatibility complex (MHC) class I molecules in epithelial stem cells adjacent to the basement membrane, but strong MHC staining of parabasal cells. ${ }^{39}$ Hence, MHC class I molecules could be involved in the recognition of the Thy-1 ligand, as they have the MHC I-associated peptide containing a tissue-specific signature. ${ }^{92}$ From this point of view, such tissue-specific peptides may be released to attract by chemotaxis the migration of Thy- $1^{+}$vesicles to target tissue cells. This implies that there are tissue-specific moieties in Thy-1 molecules.

In ovarian follicles, the Thy-1 vesicles secreted by pericytes associated with the follicular basement membrane migrate and release their content among granulosa cells and not among adjacent theca cells. ${ }^{28} 0 \mathrm{n}$ the contrary, Thy-1 vesicles secreted by pericytes of thecal vessels migrate and release their content among these thecal cells. ${ }^{32,42}$ In stratified squamous epithelium, Thy-1 vesicles from pericytes in the lamina propria migrate through the basal layer of epithelial cells and release their contents after reaching the relatively distant parabasal layer (Figure1C).

Targeted delivery of some growth factors and cytokines by intercellular Thy-1 vesicles may be enabled by tissue specificity of Thy-1 glycoprotein carbohydrate moieties ${ }^{93}$ recognizing tissue-specific peptides. Each tissue creates unique sets of glycoforms, i.e. the same peptides but carrying oligosaccharides that differ either in structure, site location or both. ${ }^{94}$ The targeted delivery of differentiation promoting substances is much more effective in delivering cytokines to specific targets compared to generally (non targeted) functioning endocrine or paracrine signaling.

\section{Homing of intraepithelial dendritic cell precursors and T lym- phocytes}

The interaction of $\mathrm{CD}^{+} 4^{+}$pMDC with endothelial cells in TCU (red arched arrow, Figure 1A) may stimulate endothelial signaling for homing of T lymphocytes (T, Figure 1A) and monocyte-derived dendritic cell precursors (DCP), which differentiate into mature dendritic cells in the intermediate layer of the stratified squamous epithelium (see complete TCS pathway below). Peripheral T and B lymphocytes, i.e., lymphocytes found outside the central lymphoid organs (thymus and bone marrow), are found not only in classical lym- phoid tissues (lymph nodes and spleen), but also in epithelia and subepithelial tissues of the skin, intestinal tract, respiratory tract, and genitourinary tract. $^{62}$ In these tissues the intraepithelial extrathymic T cells and DCP originate from self-renewing cells in cryptopatches of the subepithelial lamina propria (LPC and red arrows, Figure 1A). ${ }^{12}$ Although the interstitium of these tissues exhibits many lymphocytes, few data on such cells are available. In the liver, interstitial extrathymic $\mathrm{T}$ lymphocytes and MDC are activated during liver regeneration, and they may be responsible for regulation of cell differentiation..$^{80,95} \mathrm{On}$ the other hand, IEL, that are predominantly T lymphocytes $\left(\mathrm{CD}^{+}\right)$with $\mathrm{CD}^{+}$cells predominating most, have been more thoroughly studied.

Both T-cell TCR $\alpha / \beta$ and TCR $\gamma / \delta$ T lymphocytes are found within IEL populations, the former representing mainly T lymphocytes differentiated within the thymus, the latter $\mathrm{T}$ lymphocytes mainly of extrathymic origin. ${ }^{63}$ Intestinal $\gamma / \delta$ intraepithelial T cells develop in mice lacking a thymus, all lymph nodes, Peyer's patches, and isolated lymphoid follicles, but not gut cryptopatches, which are a pivotal birthplace of mature $\mathrm{T}$ cells such as the thymus-independent intestinal intraepithelial T cells..$^{96}$ These cryptopatches play a role in the early extrathymic maturation of intestinal intraepithelial T cells, and their absence leads to a lack of $\gamma / \delta$ intraepithelial T lymphocytes. ${ }^{97}$

During ontogeny, gut-associated lymphoid tissue develops before thymus, and it may be viewed that the gut-associated lymphoid tissue represents a more primitive lymphoid compartment. The finding that $\gamma / \delta$ intraepithelial T lymphocytes have a restricted repertoire is consistent with the idea of a primitive function. Tissue-committed intraepithelial T lymphocytes recognize tissue-specific antigens and undergo differentiation under the influence of intraepithelial MDC. They are also influenced by epithelial cells, the intercellular matrix, and soluble mediators - cytokines and immunoglobulins. ${ }^{63}$ Many lymphokines produced by intraepithelial T lymphocytes directly influence epithelial function (IFN- $\gamma$, TNF- $\alpha$, and TGF- $\beta$ ) and intraepithelial T lymphocytes exhibit alloreactivity and virus-specific cytotoxicity, provide B-cell help, and regulate epithelial cell differentiation and function. ${ }^{62,98}$

HLA-DR ${ }^{+}\left(\mathrm{DR}^{+}\right) \mathrm{DCP}$ and $\mathrm{CD} 8+\mathrm{T}$ cells interact and accompany differentiation of epithelial cells. The epithelial lamina propria contains clusters of $\mathrm{DR}^{+} \mathrm{DCP}$ lacking CD1a of mature $\mathrm{DC}$ and $\mathrm{CD}^{+} \mathrm{T}$ cells interacting themselves. ${ }^{12}$ These clusters resemble cryptopatches of the intestinal lamina propria small clusters containing two main cell types, dendritic type cells and early extrathymic T cells. ${ }^{99}$

We proposed that the epithelial lamina propria contains clusters of DCP and T cells 
resembling intestinal cryptopatches. ${ }^{12}$ These lamina propria resident clusters may serve for self renewal of epithelium-committed DCP and $\gamma / \delta$ T cells. The arrows in inset Figure 1B show numerous $\mathrm{Ki}^{+} 7^{+}$cells in epithelium lamina propria. In contrast to thymic involution in aging, ${ }^{100}$ cryptopatches increase in number and are transformed into more complex structures - the isolated lymphoid follicles with altered cellular composition ${ }^{101}$ suggesting a contribution to functional tissue alteration in the aging process.

\section{Benefits of autoreactive IgMs and IgG}

Autoantibodies, or natural antibodies against self, are present in healthy individuals and animals. It is thought that antigens recognized by natural autoantibodies and by conserved $\mathrm{T}$ cell reactivities are necessary for the selection of natural $\mathrm{B}$ and $\mathrm{T}$ cell repertoires and for the maintenance of tolerance to self. ${ }^{102}$ These natural antibodies are almost exclusively IgMs, but some are IgG. ${ }^{103}$ IgM antibodies appear earlier in phylogeny and ontogeny than IgG.

Shark immunoglobulins resemble mammalian IgM in structure and gene similarity, ${ }_{104}$ for example IgM may comprise as much as 50\% of serum proteins in the shark. By contrast, in humans IgM comprises less than 5\%. Human IgM autoantibodies have little dependence on thymic function for expression, and increase with age. Sharks and humans possess IgM antibodies that react with thyroglobulin and single-stranded DNA. Affinity-purified natural shark antibodies to thyroglobulin or singlestranded DNA constitute small fractions of the total IgM. They illustrate extensive cross-reactivity comparable to that shown by polyspecific IgM natural antibodies produced by human B cells $\left(\mathrm{CD}^{+}\right)$appearing early in ontogeny. ${ }^{103,104}$

In human sera, the reactivity of natural IgM and IgG to epidermal keratins varies among healthy individuals, binding most often to the suprabasal layers and the stratum corneum. ${ }^{105}$ Naturally occurring antibodies and autoantibodies usually mediate tissue injury only after an organ has been subjected to stressors such as ischemia. ${ }^{106}$ Natural IgM autoantibodies appear in the absence of antigenic stimulation, and are secreted by the long-lived selfrenewing B1 subset of B cells. A large proportion of these autoantibodies is reactive to phylogenetically conserved structures, such as nucleic acids, heat shock proteins, carbohydrates, and phospholipids. ${ }^{107}$

When available, autoantibodies may contribute to the regulation of epithelial cell differentiation by binding to certain epithelial cells. IgMs are present throughout the stratified squamous epithelium and have shown an increased affinity (binding) for certain epithelial sublayers. IgMs may regulate early (IgM ${ }^{1}$, stage 4), mid ( $\operatorname{IgM}^{2}$, stage 7), and late differentiation (apoptosis) of epithelial cells ( $\operatorname{IgM}^{3}$, stage 9) - see below.

\section{The complete tissue control system pathway}

Stratified squamous epithelium of the uterine ectocervix differentiates from basal stem cells (sc, Figure 2A) into young (parabasal), mature (intermediate), and aged (superficial) cells, separated by three interfaces $(\mathrm{b} / \mathrm{pb}$, $\mathrm{pb} / \mathrm{im}$, and $\mathrm{im} / \mathrm{s}$ ). Basal stem cells represent stage 1 (s1) of epithelial cell differentiation. According to TCS interactions, the layer of young cells can be divided into lower (s2), mid (s3), and upper (s4) layers. The layer of mature cells can be divided into the lower (s5), mid (s6), and upper (s7) layers. Aged cells consist of lower (s8) and upper (s9) cell layers (Figure 2A). ${ }^{12}$

Our studies ${ }^{12,39}$ show that transitions to the higher differentiated state (red arrows, Figure 2B) are dependent on distinct TCS elements recognizing stage-specific markers on epithelial cells (indicated by triangles with distinct patterns). Stem cell division is induced by $\mathrm{CD}^{+} 4^{+}$pMDC (PM, Figure 2B). Asymmetric division (s1-s2) requires the assistance of $\mathrm{T}$ cells (T). Stage s2-s3 transition is enabled by vascular pericytes secreting intercellular Thy-1 vesicles, s3-s4 by DCP secreting HLA-DR, s4-s5 by $\operatorname{IgM}$ binding $\left(\operatorname{IgM}^{1}\right)$, s5-s6 by IEL secreting CD8, s6-s7 by dendritic cells (DC) secreting CD68, s7-s8 by another IgM binding $\left(\operatorname{IgM}^{2}\right)$, and $s 8$-s9 by IgG. Apoptotic surface cells show additional binding of $\operatorname{Ig} M\left(\operatorname{Ig} M^{3}\right)$.

During the complete TCS cycle three cell types are destined to undergo apoptosis (marked $>$ X): IEL, DC, and surface epithelial cells. A complete TCS pathway requires a death of immune system-derived IEL and DC to stimulate advanced differentiation of epithelial cells. Because of apoptosis of these cells, additional new IEL and DC must be provided for continuation of differentiation/ replacement of epithelial cells.

The surface of squamous epithelium, exposed to environmental threats, does not contain T cells and MDC but shows strong surface and cytoplasmic binding of IgM and IgG. These antibodies may be naturally occurring, monoclonal polyspecific autoantibodies capable of binding multiple unrelated antigens, including bacterial antigens and toxoids. ${ }^{108}$ If so, they may be the first line of defense against bacterial environmental threats. In addition, normal epidermal stratum corneum exhibits binding of IgM and IgG autoantibodies isolated from normal human sera. ${ }^{105}$ Moreover, mucosal surfaces are protected by IgG and pentameric IgM. ${ }^{109,110}$ If such autoantibodies are polyspecific, the entire body external surface and mucosal internal surfaces are similarly protected.

The hierarchy of TCS related elements in stratified epithelium resemble their appearance during phylogeny and ontogeny. Monocytes/tissue macrophages exist in virtually all animals, including invertebrates. ${ }^{111} \mathrm{In}$ humans, primitive macrophages first develop during yolk sac hematopoiesis, and MDC are the first differentiated blood cells found in liver sinusoids by the $7^{\text {th }}$ week of gestation. ${ }^{112}$ In the brain, they appear early, during the second month of embryogenesis. ${ }^{113}$

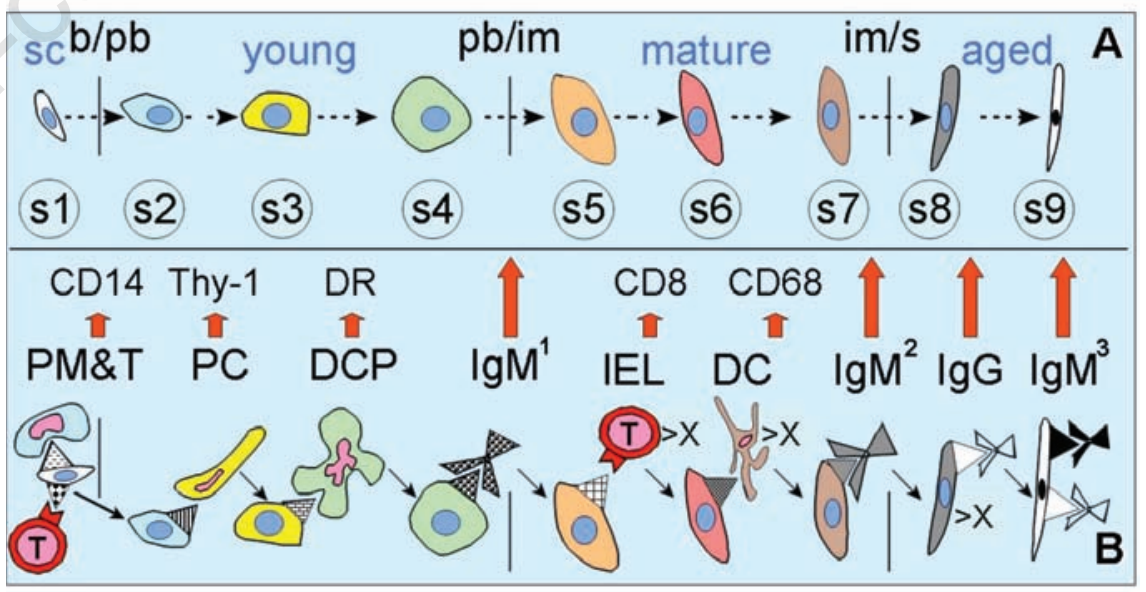

Figure 2. Hierarchy of cellular differentiation and tissue control system (TCS) elements. Complete set of nine stages (s1-9) of cell differentiation (A); b/pb - basal/parabasal, pb/im parabasal/intermediate, im/s - intermediate/surface epithelial cell interfaces. B) The cells are guided by distinct TCS elements for differentiation from stem cells (s1) to apoptosis (s9). An asymmetric division of the stem cell, giving rise to a new stem cell (s1) and differentiating cell (s2) daughters, requires involvement of both, the primitive MDC (PM) and the $\mathrm{CD8}^{+} \mathrm{T}$ cell (T) or DCP. $>\mathrm{X}$ indicates a way toward apoptosis of intraepithelial $\mathrm{CD3}^{+} / \mathrm{CD8}^{+} \mathrm{T}$ cells, DC, and surface epithelial cells. PC, pericytes; IEL, intraepithelial leukocytes. Adapted from $^{12}$ with permission, ${ }^{\odot}$ Oxford: Wiley-Blackwell Scientific Publications. 
Thy-1 differentiation glycoprotein enabling targeted delivery (recognition at cell surface) of growth substances released from pericytes (see above) has been detected in invertebrates, ${ }^{114,115}$ and embryonic blood vessels are composed of endothelial cells and pericytes that organize and expand into highly branched conduits. ${ }^{116}$ More differentiated MDC, the DCP presenting antigens to peripheral blood leukocytes and $\mathrm{T}$ cells capable of mixed leukocyte reaction are ubiquitous among the vertebrates. ${ }^{117,118}$ The immune response in mammals does not mature until the late prenatal or early postnatal period. ${ }^{119,120}$ Compared to IgG, IgM molecules appear earlier in phylogeny and ontogeny. ${ }^{104,121}$

Taken together these observations indicate that the hierarchy of TCS elements within the stratified squamous epithelium reflects their phylogenetic and ontogenetic appearance, with MDC being the first, since they accompany proliferation of tissue stem cells, and the IgG being the last involved in the regulation of tissue cell differentiation, since it accompanies apoptosis of tissue-specific cells.

\section{Autoimmunity and regulation of tissue differentiation}

Monocyte-derived DC are considered to play a role in resistence to infection and cancer and can cause autoimmunity, allergy, and graft rejection. Maturing DC loaded ex vivo with microbial or tumor antigens may combat disease, and TGF-beta, retinoic acid, rapamycin or steroids may have a tolerogenic effect on DC loaded with antigens. ${ }^{122}$

Nevertheless, it is unclear why on one hand the presence of DC and T cells is beneficial to the advanced differentiation of stratified epithelium cells while their interaction with pancreatic beta cells causes autoimmune type 1 diabetes. Autoimmunity is usually tissuespecific, and its cause could simply be a stimulation of differentiation of tissue-specific cells into a stage higher than required for normal function. While stratified squamous epithelium exhibits all nine stages of epithelial cell development, many other normal tissues show ceassation of tissue cell differentiation at a certain stage, i.e., they are stimulated to differentiate to the stage optimal for their normal function, but not further. Interaction of the TCS in differentiation of particular tissue depends on two main criteria. Firstly, not all tissue-committed immune system-related cells (DCP, T cells, and B cells producing autoreactive IgM and IgG) may be available for a particular tissue. For instance growing ovarian follicles show an association of activated vascular pericytes and HLA-DR+ MDC with their follicular basement membrane. During follicular regression, MDC invade the granulosa cell layer, but no T cells are present. On the other hand, ovar- ian CL regression is initiated by the invasion of $\mathrm{T}$ cells and terminated by binding of IgG to luteal cells. ${ }^{33,42}$

Secondly, the interaction of immune system and other TCS components, including autoantibodies, depends on the expression of appropriate ligands on tissue-specific cells (see distinct triangles in Figure 2B). For instance, Figure 1C shows that the Thy-1+ vesicles release their contents after reaching parabasal cells, but not during their migration through the basal layer. This indicates that basal cells do not express a ligand for Thy- $1^{+}$vesicles. In addition, autoreacive IgG binds to epithelial cells in the superficial layer of the cornified squamous epithelium, but not to the less differentiated cells. ${ }^{39}$ This indicates that less differentiated epithelial cells do not express a ligand for autoreactive IgG.

\section{Stop effect of monocyte-derived cells and the tissue control system- mediated tissue functional state}

MDC are felt to play a dominant role in the regulation of differentiation of tissue-specific cells. ${ }^{38}$ Intraepithelial MDC may influence the expression of ligands on epithelial cells (Figures 2A and 2B). Our observations ${ }^{12,39}$ indicate that DCP secrete HLA-DR among epithelial cells in the mid-parabasal cell layer (stage 3 ), and the resulting upper parabasal layer shows binding of $\operatorname{IgM}^{1}$ (stage 4 ). Also, DC secrete CD68 in the mid intermediate layer (stage 6), and the resulting upper intermediate layer shows binding of $\operatorname{IgM}^{2}$ (stage 7). ${ }^{39}$ Similarly, IgM binds to luteal cells in the young CL but not to the mature luteal cells, and then binds again to luteal cells in the regressing CL. ${ }^{42}$

Circulating IgG type reactive autoantibodies are studied using electroblots prepared from rat spinal cord proteins. In Alzheimer disease, such circulating antibodies were found in 57\% of patients and $30 \%$ of normal controls. When the reactivity of these autoantibodies was tested on human brains, the binding was detected in Alzheimer disease and no binding was observed in control brain tissue. ${ }^{123}$ Autoreactive IgG deposits were detected in brains of patients with Alzheimer disease but not in brains of normal aging controls, ${ }^{124}$ with strong binding to amyloid perivascular plaques. ${ }^{125}$ This suggests that patients with Alzheimer disease exhibit IgG binding ligands in the brain which are absent in normal aging brains. As a consequence of a lost stop effect of the brain MDC (microglia), the neuronal cells may undergo apoptosis and degenerate into stage 9 after IgG binding, like the superficial layer in the stratified epithelium, ${ }^{39}$ Figure 2B.

In addition, the monocyte-derived DCP, also known as monocyte-derived accessory cells with a veiled morphology and movement pattern or veiled cells, ${ }^{126}$ are capable of leaving the epithelium and entering afferent lymph channels to the draining lymph nodes, where they modulate reactivity of $\mathrm{T}$ cells and the production of immunoglobulins. ${ }^{127}$ Through multiple pathways DC apoptosis in lymph nodes regulates the balance between tolerance and immunity. ${ }^{128}$

Therefore, it depends on the properties of monocyte-derived veiled cells or DC entering draining lymph nodes as to whether or not autoreactive T cells and antibodies toward certain tissues are produced. From this point of view, the T cells and B cells are effectors of monocyte-derived cells. Intraepithelial DCP interact with homing $\mathrm{T}$ cells, causing activation (DR expression) apoptosis and CD8 release at a certain layer of the epithelium (above pb/im interface - Figure 2B). This is accompanied by differentiation of epithelial cells in the lower intermediate layer (stage 5) and differentiation of DCP into DC with CD68 release in stage 6 epithelial differentiations.

Development, differentiation, and proliferation of resident MDC are regulated by the tissue microenvironment, including the in situ production of macrophage growth factors in both fetal and adult life. Resident MDC are a long-lived, self proliferating, and renewing population. ${ }^{129,130}$ In particular tissue environments or under specific stimuli MDC can down-regulate immune response development. This is not only important for preventing overactivity of the immune system but also for ensuring tolerance against self. ${ }^{129,131}$

In stratified epithelium, we do not find any Ki67+ cells, except for postmitotic epithelial cells in the parabasal layer (arrowheads, inset in Figure 1B). However, the adjacent lamina propria contains numerous $\mathrm{Ki}^{+}{ }^{+}$cells (arrows) and clusters of many DR ${ }^{+}$DCP, some of which enter the epithelium. A long-lived and self-proliferating population of resident MDC ${ }^{129,130}$ may be constituted by the $\mathrm{DR}^{+} \mathrm{DCP}$ in the epithelium lamina propria or in the stroma adjacent to tissue-specific cells in other tissues.

Resident self-renewing MDC may exhibit a stop effect interrupting the complete TCS pathway toward differentiation of tissue cells at a particular stage. ${ }^{38}$ This stop effect can be encoded in self- renewing resident MDC by the end of the developmental immune adaptation (see below). The stop effect determines the highest state of epithelial cell differentiation allowed for a particular tissue.

Figure 3A shows the low stop effect exerted by $\mathrm{CD} 14^{+} \mathrm{pMDC}$, reflecting vaginal epithelium atrophy in postmenopausal women, where epithelial cells lacking estrogen differentiate into the (para)basal cells only. ${ }^{132}$ This may be caused by an inability of $\mathrm{CD} 14^{+}$pMDC in the vaginal lamina propria to activate Thy- $1^{+}$vesicle release from vascular pericytes (see arched green arrow, Figure 1A and arrowheads, Figure 
1C). In women with menstrual cycles (high estrogen levels), estrogens appear to by-pass the low stop effect and stratified squamous vaginal epithelium shows complete differentiation, with apoptosis of the upper superficial cells. ${ }^{133}$ However, the low stop effect of adult estrogen-dependent tissues, including vagina, is lost after estrogen exposure during the critical developmental period in mice and rats (postnatal days 0-7). Persistent vaginal cornification is induced in mice by a short postnatal treatment with estrogen. This effect is not prevented by later ovariectomy, antiestrogenic steroids, or transplantation into ovariectomized normal mice. ${ }^{134}$

During the critical developmental period mouse vaginal stromal cells in the lamina propria, but not vaginal epithelial cells, show a marked proliferative response and estrogeninduced gene expression with estrogen treatment. ${ }^{135}$ These observations suggest that estrogen independent permanent cornification of the vaginal epithelium is not caused by an alteration of the vaginal epithelial cells but by estrogen's effect on vaginal stromal cells during the critical developmental period.

In addition, women exposed to diethylstilbestrol in utero exhibit statistically significant increased risk of clear cell adenocarcinoma of the vagina and cervix. ${ }^{136}$

Figure 3B illustrates that skeletal muscle, brain, and pancreatic beta cells are usually stimulated to differentiate into stage 3 , but a stop effect (moderate SE) exerted by DCP will prevent tissue from entering stage 4 of differentiation (for cell differentiation stages see Figure 2). As discussed above, the moderate stop effect at DCP can act in two ways, e.g. i) prevent production of autoreactive IgM $^{1}$, and/or ii) prevent expression of $\operatorname{IgM}^{1}$ binding ligands on tissue cells by a lack of DR/cytokine secretion from the DCP. A lack of IgM ${ }^{1}$ binding will prevent cellular differentiation from stage 3 to stage 4. Studies of Daar and Fabre demonstrate a multiplicity of autoantibodies in virtually every normal serum examined with IgM autoantibodies against heart, liver, kidney and brain. ${ }^{137}$ A lack of DR/cytokine secretion from the DCP may prevent expression of the $\operatorname{IgM}^{1}$ ligand and is more likely to be the stop effect preventing IgM binding to these tissues under normal circumstances in vivo.

The CNS, as an immunologically privileged organ, does not require peripheral MDC and T cells, and its preservation and regeneration by the TCS is maintained by the perivascular pericytes and microglia carrying moderate stopeffect (Figure 3B).

Microglial progenitors, like peripheral MDC, arise in the yolk sac. They enter the embryo, and surround the neuroepithelium. In the developed CNS, the microglia exhibit a similarity to peripheral MDC. When CNS inflammation is induced, peripheral MDC, lacking CNS-relat- ed stop-effect, invade the brain and can be distinguished from resident microglia. A transient population of MDC recruited from the bloodstream induces progression to paralysis. During acute inflammatory CNS demyelination MDC comprise the dominant lesional cell population. ${ }^{138}$ The peripheral MDC laking proper stopeffect can cause homing of T cells accompanying neurodegenerative diseases, like Parkinson's disease ${ }^{139}$ or multiple sclerosis. ${ }^{140}$

Figure 3C shows the high stop effect exerted by intestinal DC, which allows stage 4 differentiation of intestinal epithelium with the presence of intraepithelial $\mathrm{T}$ cells and epithelial IgM $^{1}$ binding in the gut. ${ }^{110,141}$ Intestinal DC extend their dendrities between the tight junctions of intestinal epithelial cells and are very important for maintaining intestinal homeostasis. ${ }^{142}$ The stop effect of intestinal DC may prevent DC activation, which may cause inflammatory epithelial cell damage and bowel or celiac disease if unchecked. . $^{143,144}$

There might be additional more higher stop effects enabling to stop differentiation of particular tissues between stages s5, s6, s7 and $s 8$, for which we do not have any examples at present. However, there is at least one tissue lacking SE physiologically, the epidermis (Figure 3D). Proper embryonic and fetal development of epidermis are important for providing a barrier against loss of body fluids and formation of most important defense against external insults. The epidermis consists of stratified morphologically distinct epithelial cells which finally become cornified at the body surface (see stages s1-s9, Figure 2). The cornification is a result of a highly specialized form of programmed cell death. ${ }^{145,146}$ Adult type of epidermis fully develops during the critical developmental period. In human fetuses adultlike morphological differentiation (keratinization or cornification) occurs at midgestation (20-24 weeks of age). ${ }^{147}$

These observations indicate that adult epidermis lacks any SE, since it completely differentiates into apoptotic cells during the developmental immune adaptation. Importance of the immune system contribution to the epidermal differentiation is apparent in HIV patients, 20-30\% of which exhibit xerosis. In xerosis, the defective stratum corneum barrier function predisposes to repeated antigen penetra-

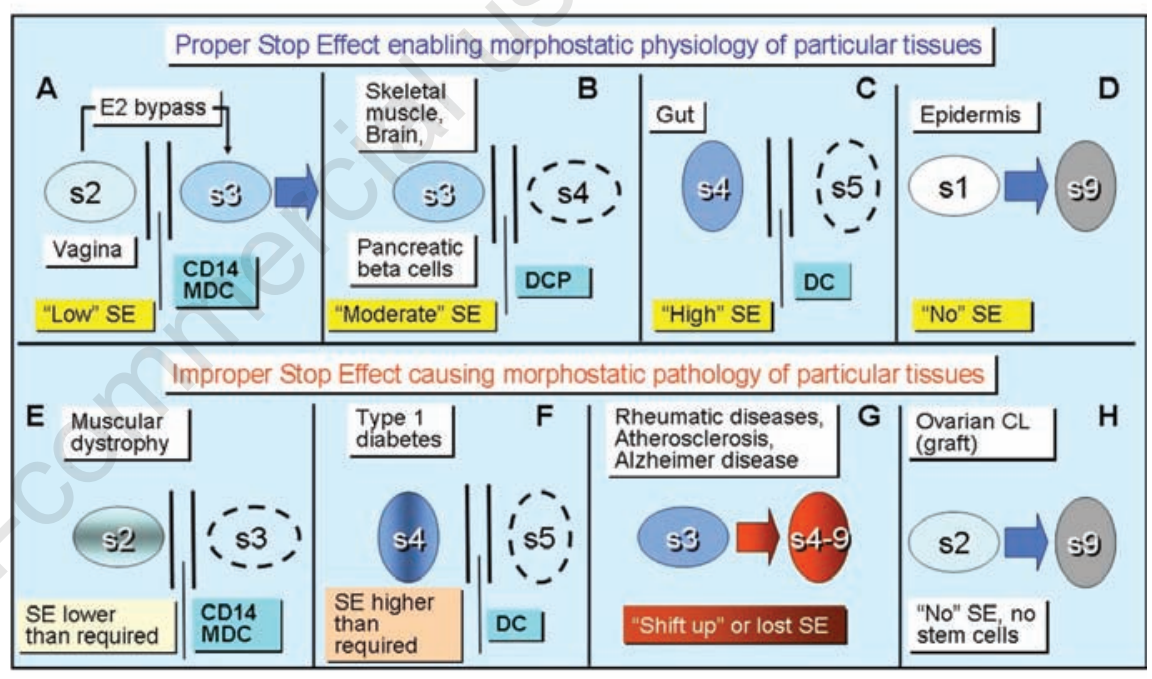

Figure 3. Stop effect (SE) of monocyte-derived cells (MDC). Stop effects of MDC prevent tissue cells to differentiate above the stage encoded by the end of the critical developmental period. Normal tissues differ at the level where the $\mathrm{SE}$ is required for their normal function (A vs B, B vs C, and C vs D). A) Low SE, for instance in the vagina, is exerted by CD14 MDC and prevents the tissue-specific cells to differentiate from stage 2 (s2) to stage 3 (s3). In some hormonally-dependent tissues the $\mathrm{SE}$ can be bypassed by a hormone (A). For instance estradiol (E2) will cause differentiation of vaginal epithelial cells from parabasal epithelial cells (s2) to aged superficial cells (s9) and lack of E2 will cause return to $s 2$ stage. B) Moderate SE, for instance in the skeletal muscle, brain, and pancreatic beta cells, is exerted by DCP and prevents the tissue-specific cells to differentiate from stage 3 (s3) to C) stage $4(s 4)$. D) The epidermis lacks any SE, since it differentiates from stem cells to apoptotic surface epithelial cells (stages s1-s9) during the critical developmental period. E) Lower setting of SE than required for normal function of particular tissue will cause tissue dysfunction due to the persisting immaturity, e.g. prevention to differentiate from s2 to 33 in the skeletal muscle will cause muscular dystrophy. F) Higher setting will cause tissue dysfunction due to its aging, e.g. differentiating cell will pass the functional stage and persist in a higher stage of differentiation than required for particular tissue function. G) The SE can be attenuated or lost with advanced age. This is accompanied by an increased incidence of autoimmune and degenerative diseases. $H$ ) Ovarian $C L$ is absent during developmental immune adaptation and, therefore, it has no SE and is managed as a graft. In addition, it does not contain its own stem cells. Adapted from ${ }^{12}$ with permission, ${ }^{\odot}$ Oxford: Wiley-Blackwell Scientific Publications. 
tion, leading to skin inflammation, and such situation has been termed as inside-to-outside pathogenesis. ${ }^{148}$

Setting the stop effect during developmental immune adaptation for particular tissue lower than required possibly creates persisting tissue immaturity, such as permanent muscular dystrophy (Figure 3E vs 3B). Duchenne muscular dystrophy exhibits a deficiency of a sarcolemmal-associated proteins ${ }^{149}$ and appear to be caused by an inability of vascular pericytes to stimulate proper differentiation of muscle cells. ${ }^{150} 0 \mathrm{n}$ the other hand, if the stop effect is set higher than necessary (Figure 3F vs 3B), homing of $\mathrm{T}$ cells to pancreatic beta islets will occur, resulting in type 1 diabetes mellitus as pancreatic islet beta cells differentiate higher than required for their normal functioning (stage 4 instead of stage 3 ).

\section{Functional immaturity or premature aging}

Tissue-specific stop effects of MDC are expected to be established epigenetically during developmental immune adaptation (critical developmental period) ending at about 6 months of intrauterine life in humans and 7 days of postnatal life in mice and rats. ${ }^{119}$

The epigenetic events of MDC involved in the process may include alteration in the DNA transcription pattern by histone acetylation and methylation and correlations with mRNA. Epigenetic mechanisms alter the cell's phenotype (gene transcription) without altering its genotype. Therefore, epigenetic alterations during critical period of development are not genetically transmitted but are involved in programming, impacting the health of a given individual. Gene transcription is influenced by modification of surrounding histone proteins and the methylation pattern of DNA. Specific modulators influence histone-modifying effector enzymes. ${ }^{151}$

Overfeeding during developmental immune adaptation resulting in a metabolic syndrome phenotype (obesity, hyperlipidemia, hyperglycemia, hyperinsulinemia, and an increased insulin/glucose ratio) is caused by an alteration of the DNA methylation pattern. ${ }^{152}$ Aberrant histone lysine methylation patterns that change chromatin structure thereby promote dysregulated gene transcription and disease progression.

As indicated above, estrogen injection during developmental immune adaptation permanently alters vaginal stromal cell rather than epithelial cell properties. Diabetic conditions mimicked by culturing THP-1 MDC in high glucose concentrations lead to dynamic changes in histone $\mathrm{H} 3$ lysine acetylation ${ }^{153}$ and methylation. ${ }^{154}$ Relevance to human diabetes was demonstrated by showing that histone $\mathrm{H} 3$ lysine 4 dimethylation at the coding and pro- moter regions of two candidate genes was significantly greater in the blood MDC of diabetic patients compared to normal controls, similar to the THP-1 MDC data. Moreover, regular mRNA profiling with cDNA arrays revealed correlations between mRNA and lysine 9 dimethylation levels. ${ }^{154}$ In addition, lymphocytes of patients with type 1 diabetes displayed a distinct profile of chromatin histone $\mathrm{H} 3$ lysine 9 dimethylation when compared to lymphocytes from control subjects. ${ }^{155}$

These observations indicate that gene transcription of MDC is altered in vitro by high glucose conditions. In women exhibiting high glucose levels during pregnancy such altered MDC gene transcription could be encoded in the fetus during developmental immune adaptation and persist thereafter, similar to the altered circulating MDC in diabetic patients. Since MDC regulate properties of T cells, gene transcription is likewise affected in T cells of diabetic patients. This results in inflammatory gene transcription with alteration of the pancreatic beta cells and the resultant diabetic condition.

Estrogen inhibition of ovarian differentiation during developmental immune adaptation in postnatal female rats causes ovarian immaturity in adults. ${ }^{44}$ This suggests that perhaps muscular dystrophy (Figure 3E) could be caused by a retardation of muscle development during developmental immune adaptation.

On the other hand, stimulation of advanced ovarian differentiation by androgens during developmental immune adaptation in postnatal rats results in a persistence of prematurely aged ovaries in adults. ${ }^{43}$ This suggests that the type 1 diabetes (Figure $3 F$ ) could be caused by a stimulation of advanced pancreatic beta cell differentiation during developmental immune adaptation.

Figure $3 \mathrm{E}$ demonstrates consequence of lower stop effect not allowing the tissue to reach a functional stage and Figure $3 \mathrm{~F}$ higher stop effect where the tissue cells are passing their functional stage in particular tissue and enter dysfunctional condition.

Neither type of ovarian dysfunction can be induced after termination of the adaptative period, e.g., in 10 day old postnatal rat females. ${ }^{43,44}$ However, there are differences depending on whether ovarian development is inhibited by estrogens earlier (postnatal days 0-3 ) or later (days 3-6), before the end of the developmental immune adaptation. In earlier injected females, the persisting ovarian failure is permanent but later injected animals begin to ovulate later than after puberty, at 8 months of age. ${ }^{156}$

This suggests that persisting ovarian immaturity can result in a delay of normal ovarian function if ovarian development is inhibited shortly before the end of the developmental immune adaptation. Therefore one may expect that the stop effect has a tendency to shift up with advancing age. This shift up of the stop effect with age could cause an increased incidence of autoimmune/degenerative diseases, where the stop effect is higher than required (autoimmnity) or lost (degenerative diseases) (Figure 3G).

Consequences of cellular differentiation during developmental immune adaptation for tissue function are summarized in Figure 4, showing four possible variants (A-D). Retardation during developmental immune

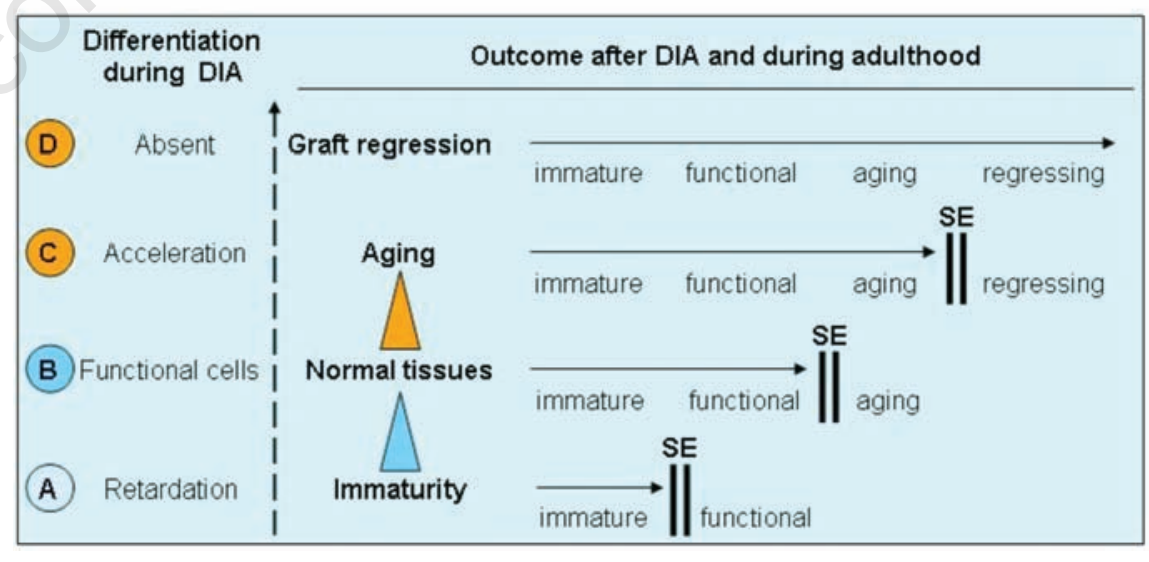

Figure 4. Stop effect of monocyte-derived cells (MDC)and the critical developmental period. Stop effect of MDC for each tissue is set during developmental immune adaptation (DIA) and determines characteristics of tissue function thereafter. Functional cells represent a stage of development optimal for particular tissue and they differ between tissues, ranging from stage $s 1$ (vagina) to stage $s 9$ (no stop effect in epidermis - see Figures 2 and 3). Retardation of optimal tissue development during DIA causes persistent tissue dysfunction due to the immaturity, i.e., the differentiating tissue cells do not reach a functional stage. Acceleration of optimal tissue development during DIA causes persistent tissue dysfunction due to aging, i.e., the differentiating tissue cells pass the functional stage and are preserved as aged cells. Tissues absent during DIA, like ovarian CL, are handled as a graft. Orange arrowhead indicates a tendency of the SE to move higher than necessary with age advancement. Adapted from ${ }^{43}$ with permission, ${ }^{\circ}$ Elsevier. 
adaptation (DIA, Figure 4A) will result in persisting immaturity, where the stop effect is set lower than required for functional cells in a particular tissue. Interestingly, muscular dystrophy does not affect all muscles of the body, but different types of muscular dystrophy show different symmetric areas of muscles affected by a muscle weakness. ${ }^{149}$ This may be due to the selective retardation of certain muscles during particular periods of their development and subsequent self renewal of corresponding resident MDC carrying the stop effect causing persistent muscle immaturity.

Regarding differentiation of functional cells (Figure 4B), the tissues vary in their optimal stage of tissue-specific cell differentiation required for proper function, including a lack of the SE (Figure 3A-D). Proper differentiation will enable tissue cells to be preserved in a functional stage and prevented from immaturity or aging. Acceleration of tissue differentiation during developmental immune adaptation (Figure 4C) will cause persisting premature aging due to the autoimmunity. The higher than required stop effect still prevents a tissue from complete regression, which occurs in tissues like ovarian CL lacking stop effect, since such tissue was absent during developmental immune adaptation (Figure 4D).

The CL is probably the only structure in the body, which is required to develop into functional stage and regress thereafter in order to maintain the cyclicity of the ovarian ovulatory function. When compared to epidermis, which also lacks SE, the CL is absent during developmental immune adaption, and therefore maintained as a graft. ${ }^{33}$ In addition, the CL lacks its own stem cells (Figure 3H vs 3D), since it develops from follicular granulosa cells after the luteinizing hormone surge in the ovarian midcycle. There are two occasions when the CL persists - during pregnancy, which is associated with immune suppression, ${ }^{157}$ and in climacteric women, where decline of immune functions with advancing age may result in incomplete regression of luteal tissue. ${ }^{34}$ The dashed arrow in Figure 4 indicates a tendency of the stop effect to shift upward with the age advancement.

\section{Stop effect shift up with age advancement}

As indicated above, certain tissues contain lymphoid structures resembling intestinal cryptopatches, consisting of self-renewing MDC and eventually also extrathymic T cells. These structures are thought to carry the tissue-specific stop effect at the level of selfrenewing $\mathrm{MDC} .{ }^{12}$ As indicated above, when compared to young animals, cryptopatches are unexpectedly found to increase in number and complexity in aging individuals. Isolated lymphoid follicles show an altered cellular composition and immunoglobulin production. ${ }^{101}$
Since monocyte-derived veiled cells are involved in the regulation of $\mathrm{T}$ cell function and production of immunoglobulins, we suggest that the age associated dysfunction of tissues is due to the shift of the stop effect to a higher level than required for normal function. This may cause age-associated alteration of tissues, such as autoimmunity, rheumatic diseases, atherosclerosis, and Alzheimer disease - see Figure 3G. Due to the shift up of the stop effect, the MDC become activated toward secretion of DR, create a residence of T cells, or enable binding of immunoglobulins in tissues where these actions are abnormal.

\section{Determination of tissue functional longevity}

The developmental immune adaptation was first described in 1945 by Owen, who demonstrated that genetically dissimilar red blood cells coexisted in freemartin cattle. ${ }^{158} \mathrm{He}$ postulated that such cells were exchanged within the shared placenta via vascular anastomoses. In 1953 erythrocytic chimerism was also reported in a dizygotic human twin. ${ }^{159}$ In addition, in 1953, an artificial induction of immunological tolerance was first accomplished by Hasek and Medawar. Milan Hasek joined the circulatory systems of two chicken embryos in their corresponding eggs, and proved that the hatched birds were chimeras that tolerated each other's tissues. ${ }^{160}$ Sir Peter
Brian Medawar and colleagues intravenously injected spleen cells of mouse $\mathrm{X}$ strain into newborn mice of strain $\mathrm{Y}$ and than demonstrated that the adult Y-strain mice tolerated Xstrain skin grafts. ${ }^{161}$ During developmental immune adaptation, through the end of the second trimester of intrauterine life in humans, ${ }^{119}$ differentiating tissues are recognized by the developing lymphoid (immune) system as self.

As indicated above, the developmental adaptation (DIA, Figure 5) is a period of early life during which a character of function of various tissues during further life is epigenetically programmed. ${ }^{54,55}$ In rats and mice, the sensitivity to androgen-induced premature aging of adult ovaries and estrogen-induced persistent ovarian immaturity is terminated after the first postnatal week..$^{43,44,162}$ In addition, at the end of the first postnatal week, the mouse ovary exhibits maximum number of oocytes and primordial follicles. More than half of the primordial follicles that are formed by Day 6 of postnatal life in the mouse will be eliminated from the ovary by the time of puberty. Hence, at the end of the developmental immune adaptation, the substantial extinction of ovarian oocytes is initiated. Accordingly, maximum oocytes in human fetal ovaries (5-7 millions) are present in the sixth fetal month, and they are reduced to 1 million till the birth. This suggest that substantial reduction of oocytes is initiated in both species after the termination

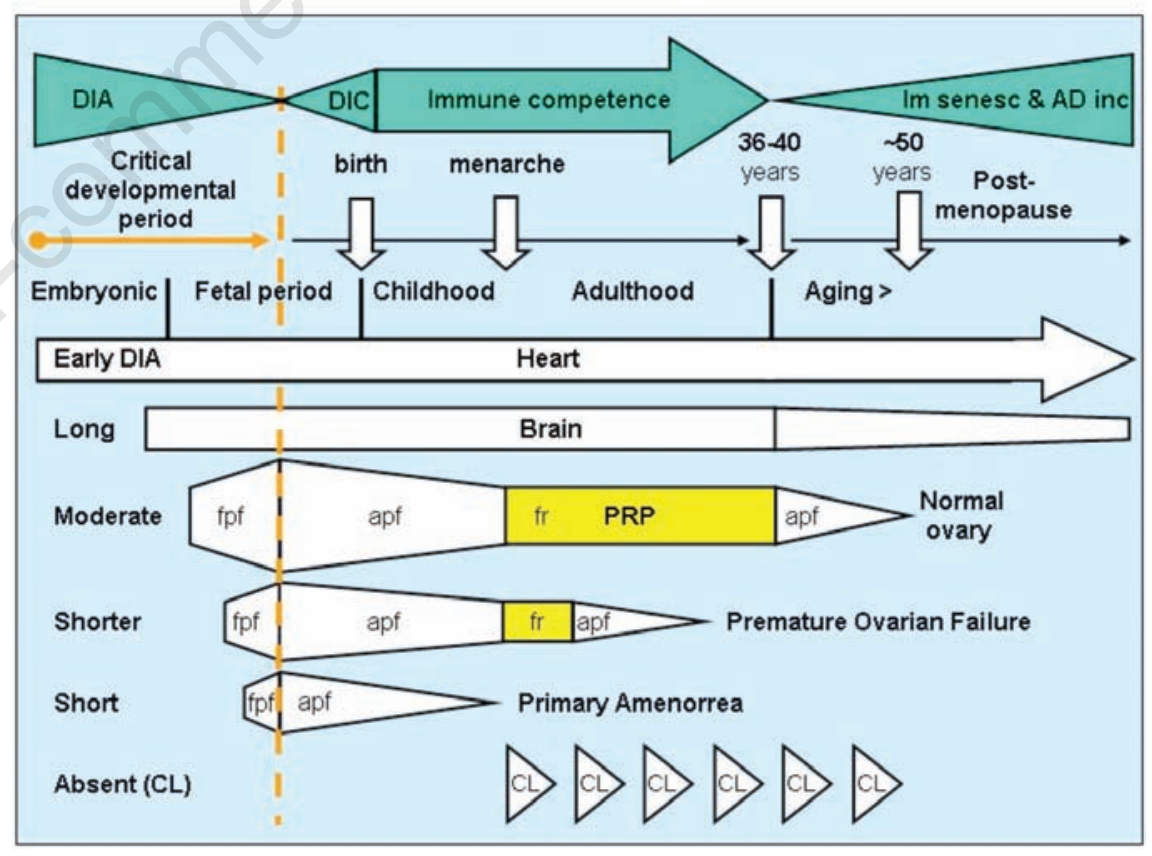

Figure 5. Critical developmental period and tissue longevity. The earlier the tissue differentiates during developmental immune adaptation (DIA), the longer it functions. After the DIA is terminated, the developmental immune competence (DIC) develops. The immune competence begins to be affected from 36-40 years of age in humans. Most early developed is the heart, long DIA is represented by the brain, and moderate DIA by the ovary. For the ovary, the shorter DIA may result in premature ovarian failure, and short DIA in primary amenorrhea. apf, aging ovarian primordial follicles; fpf, fetal primordial follicles; fr, follicular renewal. Adapted from ${ }^{45}$ with permission, ${ }^{\odot}$ Macmillan Reference USA. 
of developmental immune adaptation.

The termination of developmental immune adaptation is not immediately followed by the developmental immune competence (DIC, Figure 5), e.g., an ability to eliminate non-self, but such termination ceases an ability to induce immune tolerance toward new antigens and causes unresponsiveness to the new artificial or environmental insults. In both, the humans and mice, the developmental immune competence appears to be attained after the second postnatal week. ${ }^{163,164}$

Interestingly, the functional period of distinct tissues during adulthood appears to be determined by the interval during which they are present during developmental immune adaptation. The heart differentiates into functional tissue from early stages of ontogeny and of developmental immune adaptation (Early DIA, Figure 5), and can function for one hundred years in humans. The brain, which differentiates prior to the end of the embryonic period $^{165,166}$ (Long DIA, Figure 5), shows increasing incidence of Alzheimer's disease after 40 years of age ${ }^{167}$ (AD inc, Figure 5). Development of the hippocampus, lesions of which occur in the Alzheimer's disease and are accompanied by memory dysfunctions, ${ }^{168}$ is delayed from other brain structures for several weeks. ${ }^{169}$ The ovary, in which primordial follicles differentiate later, can function only half as long compared to the heart. The ovarian fetal primordial follicles (fpf, Figure 5) begin to differentiate relatively late, during the $4^{\text {th }}$ month of intrauterine life (Moderate DIA). After termination of developmental immune adaptation (dashed line), aging primordial follicles (apf) persist until menarche, and normal ovarian function is limited by follicular renewal (fr) during the prime reproductive period (PRP), between menarche and 35-40 years of age. The immune system shows the beginning of significant functional decline (senescence) between 35 and 40 years of age in humans ${ }^{100}$ (Im senesc, Figure 5), and concomitantly ovarian follicular renewal wanes. ${ }^{47}$ Thereafter, aging primordial follicles are utilized until exhausted, and physiologic menopause occurs at about 50 years.

Shorter DIA periods may occur when ovarian differentiation is delayed. Consequently, follicular renewal is shorter and results in ovarian dysfunction known as a premature ovarian failure (POF) or premature ovarian insufficiency. Patients with POF have been found to have abnormalities in the function of MDC and DC, ${ }^{170}$ suggesting a relationship between the immune system and POF.

More extreme delay of ovarian differentiation could cause Short DA resulting in the lack of follicular renewal and primary amenorrhea. The absence of ovarian CL during developmental immune adaptation causes their cyclic degeneration, except during pregnancy, which is accompanied by immune suppression.

\section{Lessons from the ovarian \\ stem cell niche}

A number of studies in distinct animal species indicated that immune cells play an important role in cyclic ovarian activity and suggests that the immune system participates in the regulation of ovarian function. ${ }^{26,171}$ The ovary exhibits cyclic renewal, differentiation and regression of its functional structures. It is therefore a unique model for better understanding of the immune system's role in these processes. Ovarian function is affected relatively early during the female life, along with alteration of the ovarian SCN accompanying the early stages of immune senescence (see above). Altogether, studies of the role of the immune system in ovarian homeostasis contribute to a better understanding of the immune system's role in SCN and tissue morphostasis in general.

Ovarian stem cells in both fetal and adult human ovaries show in vivo nuclear reprogramming into the two cell types required for formation of primordial follicles and follicular renewal, the granulosa cells and secondary germ cells. ${ }^{32,47,48}$ This process is dependent on distinct SCNs. ${ }^{12}$

\section{Involvement of monocyte-derived cells and $T$ cells in the development of secondary germ cells from ovarian stem cells by asymmetric}

\section{division}

Asymmetric stem cell division enables the stem cells to maintain their quantity (symmetric stem cell daughter) and produce cells committed toward differentiation (asymmetric stem cell daughter). The mechanisms enabling such process consist of an intrinsic mechanism - asymmetric segregation of the cell fate determinants into only one of the two daughter cells, and an extrinsic mechanism orientation of the cell division plane so that only one of the two daughter cells maintains contact with the niche (stem cell daughter), and the other becomes a differentiating cell. These asymmetric stem cell division pathways have been most extensively studied in invertebrates. ${ }^{172-174}$

It appears that the maintenance of contact with the underlying basement membrane determines the symmetric stem cell fate and that lack of contact is a stimulus for the asymmetric stem cell daughter. ${ }^{175}$ The role of extrinsic spindle orientation and intrinsic asymmetric distribution of the Notch differentiation protein during mitosis has been demonstrated during the epidermal stem cell division in mice. ${ }^{81}$

How do the intrinsic and extrinsic mechanisms controlling asymmetric cell division, cell growth, and organ size function? Is there the same stem cell mechanism controlling their behavior in different tissues? Or is the asymmetric division mechanism different for distinct tissues? Why does disruption of asymmetric cell division lead to uncontrolled stem cell proliferation?

Our observations suggest that control of cell growth, differentiation, and organ size is a complex process mediated by the TCS. Such a process exhibits tissue-specific properties (Figure 3) encoded epigenetically during the adaptive period of development, and diminish with age (Figure 4). In epithelial tissues containing IEL, stem cell symmetric division is induced by the interaction of $\mathrm{CD} 14^{+}$pMDC with the cell. Interestingly, the Drosophila shows the presence of leukocyte-like cells called hemocytes with MDC/macrophage properties. ${ }^{176}$

In humans, one from resulting stem cell daughters is stimulated to differentiate by the interaction of $\mathrm{CD}^{+}{ }^{+} \mathrm{T}$ cell. ${ }^{12}$ This may be particularly important for tissues containing uncommitted intrinsic stem cells, like OSC capable of differentiating into germ cells, granulosa cells, and other cell types (see below). Pluripotency of tissue stem cells is probably more wide than expected. For instance, mouse muscle progenitor cells were shown to transdifferentiate to neurons after transplantation in developing brain. ${ }^{11}$ Porcine fetal skin stem cells have been reported to exhibit multilineage potential, ${ }^{177}$ and such cells were able to differentiate in vitro into oocyte-like and ovarian follicle-like structures. ${ }^{178,179}$ The 0ocyte-like cells from porcine fetal skin stem cells were, however, found not to be functionally competent under given culture conditions. ${ }^{180}$

In tissues lacking IEL, asymmetric division may utilize during mitosis the extrinsic spindle orientation and intrinsic asymmetric distribution of differentiation promoting proteins. Once the cell is committed toward differentiation, the additional interaction of $\mathrm{CD} 14^{+} \mathrm{pMDC}$ will stimulate symmetric division of committed cells.

Another possibility is that tissue cell precursors divide symmetrically and some of them are stimulated to differentiate by DCP. For instance in adult ovaries, the tunica albuginea fibroblast-like cytokeratin $(\mathrm{CK})^{+}$cells divide symmetrically and some are converted into granulosa cell precursors by interaction of $\mathrm{DR}^{+}$ DCP. ${ }^{12,32}$

The asymmetric division of ovarian stem cells (OSC) in human ovaries (white arrowhead, Figure 6A-D) is initiated by the interaction of CD14 MDC with OSC and release of the CD14 (arrow, Figure 6B). The resulting daughter cells are still accompanied by CD14 MDC (yellow arrowheads, Figures 6A and B), but one of them develops into a secondary germ cell (sgc and red asterisks, Figures 6A-D) in the presence of CD8 T cell (Tc and white aster- 
isk, Figures $6 \mathrm{~A}$ and $\mathrm{C}$ ) penetrating into the cytoplasm of the emerging secondary germ cell (red arrowheads). The other daughter remains in the pool of OSC (osc and yellow asterisks, Figures 6A-C). ${ }^{32}$ Figure $6 \mathrm{D}$ shows with double color immunohistochemistry that during asymmetric division of the OSC, the stem cell daughter retains cytokeratin staining (CK, blue color) and the emerging secondary germ cell daughter loses cytokeratin while expressing PS1 meiotically associated antigen (PS1, brown color).$^{47}$ In the ovarian tunica albuginea (ta, Figure 6E), the emerged germ cells exhibit symmetric division (green arrowhead) required for the crossing over of germ cell chromosomes. $^{181}$ Note strong PS1 nuclear staining. After division, the germ cells migrate (arrow) to the ovarian cortex (oc, dashed line indicates ta/oc interface). Note a development of surface staining (solid orange arrowhead) in the migrating germ cell. In the upper ovarian cortex, the germ cells associate (arrowhead Figure 6F) with cortical vessels (cv) and enter blood circulation (see below). Note a diminution of PS1 nuclear staining (asterisk) and high cytoplasmic and cell surface PS1 expression (arrow). Arrowhead indicates an intimate association of the germ cell with cortical vessel, and solid orange arrowhead shows PS1 staining of adjacent endothelial cells - see inset for detail. Except for the germ cells, the PS1 staining was not detected on any other ovarian structures.

We also found that during asymmetric division of OSC, the stem cell daughter retains major histocompatibility class I (MHC-I) antigens, while the emerging secondary germ cell daughter loses them. ${ }^{48}$ Figure 6G shows asymmetric (white arrowhead) and symmetric (green arrowhead) divisions with MHC-I depletion on emerging and dividing germ cells in midpregnancy human fetal ovaries. Figure $6 \mathrm{H}$ demonstrates an association of $\mathrm{CD}^{+} 4^{+}$ MDC (black arrowhead) with symmetrically dividing (green arrowhead) germ cells in fetal ovaries. $^{48}$

\section{The monocyte-derived cells} accompany symmetric division and migration of secondary germ cells

\section{in adult human ovaries}

In tunica albuginea (ta, Figure 7A) under the OSC of adult human ovary, the CD14 MDC (white asterisk) also accompany the symmetric division of germ cells ( $\mathrm{gc}$ and arrows) ${ }^{32}$ In adult human ovaries, ameboid-shaped germ cells leave the tunica albuginea and enter the upper ovarian cortex (uoc, Figure 7A) guided by CD14 MDC (arrowhead, Figure 7A). Ameboid germ cells migrating through the upper ovarian cortex (uoc, Figure 6B) are accompanied by $\mathrm{DR}^{+} \mathrm{MDC}$ (arrowhead), and show perinuclear DR expression (arrow). They associate with the cortical vasculature (Figure 6C) with strong MHC class I expression on the vascular endothelium (ve), and enter the vascular lumen (vl, Figure 6D) lined with Thy-1 ${ }^{+}$ pericytes (arrows). ${ }^{32}$ Vascular transport in adult human ovaries enables germ cells to reach the granulosa cell nests lining the vascular lumen in distant lower ovarian cortex and to form new primordial follicles. ${ }^{47}$

These observations show that MDC play a pivotal role in the symmetric division of germ cells and their migration toward the microvasculature in the upper ovarian cortex. Germ cells enter venules in the upper ovarian cortex and are transported toward granulosa cell nests in the distant lower ovarian cortex. Data indicate that the OSC niche is a complex process. Any failure in either the formation of granulosa cell nests, secondary germ cell formation, their subsequent symmetric division, migration, or vascular transport will cause termination of follicular renewal and subsequent ovarian failure.

\section{Nuclear reprogramming of ovarian stem cells in vitro}

In vitro, the OSC are capable of differentiat- ing into distinct cell types, including oocytes, epithelial cells, fibroblasts, and neural type cells. ${ }^{182}$ With the assistance of a satellite cell (black arrow, Figure 7E) providing the additional organelles (black arrowhead) necessary for oocyte growth and development, and a neuronal cell type (white arrow) with a dendritic extension over the oocyte (arrowhead) the germ cell differentiates into a large (150 micrometers) oocyte with germinal vesicle breakdown (gvbd, Figure 7E) and a thick zona pellucida (ZP) membrane lacking expression of ZP antigens. Such oocytes eventually differentiate into four-cell parthenogenetic embryos (Figure 7F) expressing deleted azoospermia like (DAZL) protein. The inset shows DAPI staining with two isolated nuclei (arrowheads) and a dividing cell (arrow). Also observed are DAZL $^{+}$parthenogenetic blastocysts (Figure 7G) consisting of a blastocoele (bc), trophectoderm (te), and inner cell mass (icm), the latter producing (arched arrow) large quantities of DAZL $^{+}$ESC (esc). Ovarian stem cells are capable of differentiating into oocytes regardless of the patient's age, including cells in ovaries of patients with POF. ${ }^{51,183-185}$

These observations indicate that totipotent

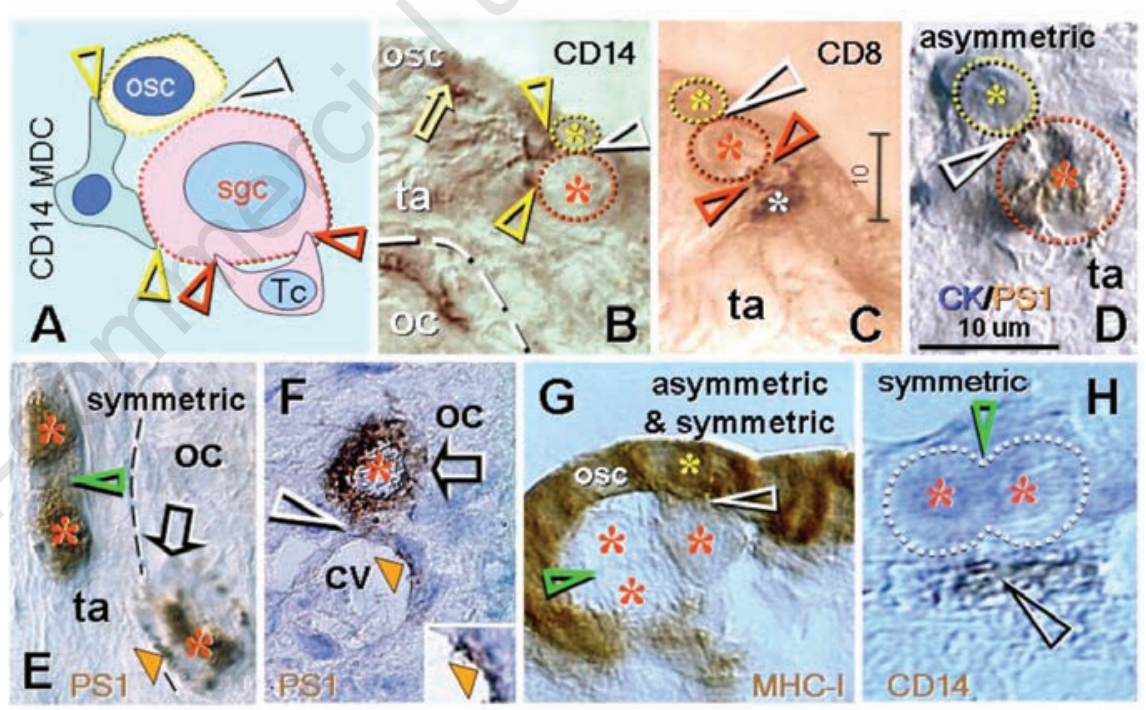

Figure 6. Role of monocyte-derived cells (MDC) and T cells in asymmetric and MDC in symmetric division of ovarian stem and germ cells in adult (A-F) and fetal human ovaries ( $G$ and $H)$. A) Asymmetric division (white arrowhead) of ovarian stem cells (osc) giving rise to a new secondary germ cells (sgc) requires involvement of CD14+ primitive MDC (yellow arrowheads) and CD8+ T cells (Tc and red arrowheads). B) CD14+ MDC (arrow) associate with ovarian stem cells and accompany (yellow arrowheads) their asymmetric division (white arrowhead). C) Asymmetric division produces stem cell daughter (yellow asterisk) among ovarian stem cells and larger germ-like cell (red asterisk) in the tunica albuginea (ta). Emergence of the latter is accompanied by the CD8+ T cell (red arrowheads). D) Stem cell daughter keeps cytokeratin (CK, blue color) expression and emerging germ cell exhibits PS1 meiotically associated antigen (PS1, brown color). E) PS1 + germ cells divide symmetrically in the tunica albuginea and migrate to the upper ovarian cortex (oc), where they associate with cortical vessels (cv, F). G) Emerging and dividing secondary germ cells (red asterisks) show a depletion of MHC-I antigens. H) Symmetric division of secondary germ cells is accompanied by CD14+ MDC (black arrowhead). Bar in C for B and C, bar in $\mathrm{D}$ for D-H. Panel A from ${ }^{12}$ with permission, ${ }^{-}$Oxford: Wiley-Blackwell Scientific Publications; $\mathrm{B}$ and $\mathrm{C}$ adapted from $^{32}$ with permission, ${ }^{\circ}$ Blackwell Munksgaard; D-F from ${ }^{47},{ }^{\odot}$ Antonin Bukovsky; $\mathrm{G}$ and $\mathrm{H}$ adapted from ${ }^{48}$ with permission, ${ }^{\odot}$ Humana Press. 
ovarian stem cells are capable of producing normal oocytes in vitro. Spontaneous parthenotes can also develop during culture of normal noninseminated follicular oocytes. ${ }^{186}$ The development of oocytes from OSC in vitro is of particular interest in regenerative medicine regarding patients with POF, since it does not require a complex OSC niche for follicular renewal in vivo (see above). In vitro developing oocytes are not accompanied by granulosa cells which penetrate deep into the ooplasm and inject additional organelles (the $\mathrm{CK}^{+}$ Balbiani body ${ }^{47,187}$ required by the oocyte in vivo. Oocyte development in vitro is enabled by fibroepithelial satellite cells, i.e. the cell type to which granulosa cells are always transformed during in vitro culture. ${ }^{50}$

Once fertilized, oocytes produce blastocysts, ${ }^{183}$ which could be utilized for in vitro fertilization to produce genetically related progeny for POF patients. Due to the lack of expression of ZP antigens on oocyte surface, the fertilization of such oocytes may require intracytoplasmic sperm injection.

\section{A role for sex steroids in the neural stem cell niche}

The age-related loss of androgens in man is associated with symptoms that include depression and impaired cognitive function. Lower free testosterone (TS) levels can be detected 510 years prior to the diagnosis of Alzheimer's disease (AD). Animal experiments suggest that both estrogens and androgens could play a role in preventing such neurodegeneration. In clinical trials to date, the most extensively studied steroids have been androgens. Androgen therapy, however, has no effect on cognitive performance, including verbal and non-verbal memory in elderly patients. In addition to the gonads, some steroids are also synthesized in adrenals and in the brain; the latter are sometimes termed neurosteroids. ${ }^{188}$

Sex steroids may have the potential to stimulate the proliferation and differentiation of existing NSC. They easily pass thru the bloodbrain barrier and bind to the abundant sex steroid receptors in the brain, particularly areas important for the regulation of emotions, cognition, and behavior. ${ }^{189}$ It remains to be determined whether utilization of a single sex steroid alone might have a role in prevention or treatment of neurodegenerative diseases and traumatic neurologic injuries.

\section{Sex steroid combinations cause nuclear reprogramming of ovarian stem cells into neural and neuronal type cells in vitro}

Our initial observations of cultured ovarian stem cells indicated that they are capable of differentiating spontaneously into distinct cell types including occasional neuronal type cells (inset, Figure 8A). ${ }^{182}$ Our subsequent experiments tested different sex steroid combinations in ovarian cell cultures..$^{50}$

Ovarian epithelial stem cells differentiate into large epithelial cells lacking the expression of stage-specific embryonic antigen (SSEA)-1 and neural cell adhesion molecule (NCAM). A few epithelial cells in untreated cultures show weak staining for Thy-1 differentiation protein (Figure 8A) abundant in neuronal cells, ${ }^{89}$ and similar expression of SSEA-4. The addition of individual gonadotropins (FSH and/or hCG), EGF, estradiol (E2), progesterone (PG), and TS alone (at 60 micro $\mathrm{M}$ for each steroid), or E2+PG and E2+TS combinations showed no change in either cell morphology or immunohistochemical staining. No changes were observed in control cultures, including those with the sex steroid vehicle..$^{50}$

On the other hand, utilization of TS mixed with PG one day after E2 pretreatment produced a marked effect one hour after the treatment. There was a transdifferentiation of epithelial cells into small cells, some strongly expressing SSEA-1 (arrowhead, Figure 8B), a glycoconjugate of neural stem cells (NSC) and precursor cells. ${ }^{190}$ An asymmetric division resulting in SSEA-1+ ${ }^{+}$and SSEA-1 ${ }^{-}$daughter cells is shown in Figure 8C. Note the stained early extensions (arrow) associated with the SSEA-1+ cell. Three hours after treatment, neuronal type cells developed and strongly expressed Thy-1 antigen (white arrowhead, Figure 8D), a GPI-anchored protein expressed by neurons. ${ }^{191}$ Many cells developed Thy- $1^{+}$ extending processes (black arrowhead), characteristic of neuronal differentiation.

Stage-specific embryonic antigen-4 (SSEA4) is commonly used as a cell surface marker of pluripotent human ESC and SSEA-4 cells
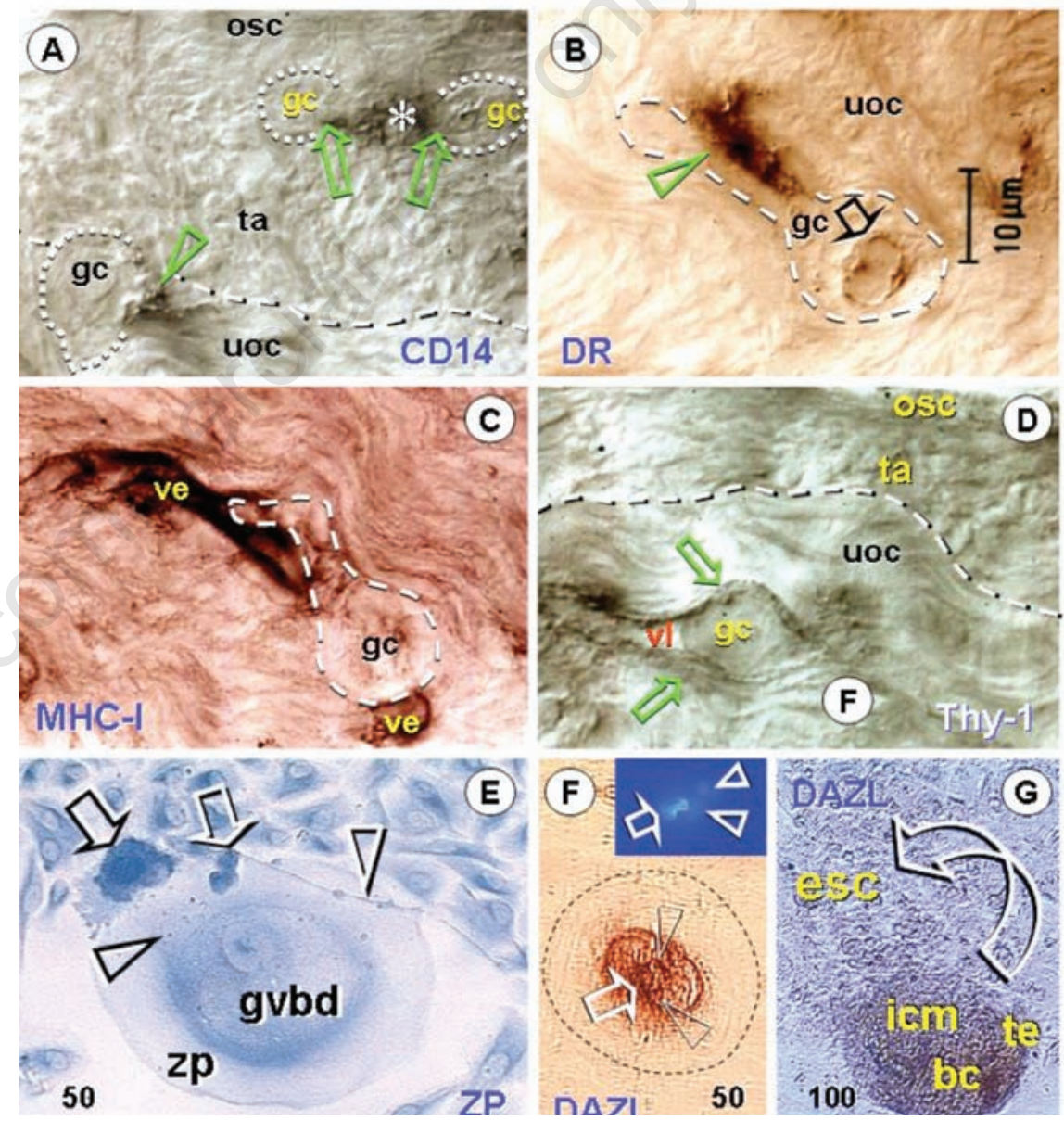

Figure 7. Migration of female germ cells in adult human ovaries and neo-oogenesis in ovarian stem cell cultures. A) In adult human ovaries, CD14+ MDC (asterisk) accompany symmetric division of germ cells (gc and arrows - see also Figure $6 \mathrm{H}$ ) and their migration (arrowhead) from ovarian tunica albuginea (ta) to upper ovarian cortex (uoc). B) HLADR+ MDC (arrowhead) accompany migration of germ cells through the uoc, toward vasculature (panel C), which they enter (panel D) in order to reach granulosa cell nests in the distant lower ovarian cortex. Cultured ovarian stem cells give a rise to the large oocyte like cells $(E)$ and parthenogenetic embryos (F and $G)$. bc, blastocyst; esc, embryonic stem cells; gvbd, germinal vesicle breakdown; icm, inner cell mass; te, trophectoderm; ve, vascular endothelium; zp, zona pellucida; Bar in panel B for A-D. Panels A-D adapted from ${ }^{32}$ with permission, ${ }^{\odot}$ Blackwell Munksgaard; E-G from ${ }^{227}$, ${ }^{\odot}$ Cambridge Journals. 
enriched in the neural stem/progenitor cell fraction. ${ }^{192}$ SSEA-4 is strongly expressed in neuronal type cell bodies (black arrowhead, Figure 8E) but not extensions (white arrowhead). Control immunohistochemistry produces no staining in neuronal or other cell types. In phase contrast observations, large numbers of putative stem cells were found to detach from the chamber bottoms floating in the center of the wells (Figure 8F). These cells show bubble-like anchoring extensions (arrowhead, Figure 8G), which apparently serve in the attachment of trypsin detached and seeded non-neuronal cells. Since such putative NSC did not attach again, such cells are capable of being transported where needed. Similar transdifferentiation was observed in porcine and human ovarian granulosa cell cultures. In vivo, pluripotent ovarian epithelial stem cells give rise to two distinct cell types, the ovarian germ cells and granulosa cells..$^{32,47}$ Granulosa cells characteristically differentiate in vitro into fibroepithelial cells. ${ }^{50}$ The treatment of long-lasting porcine granulosa cell cultures on Day 0 with EGF, hCG, and E2 alone, or with a mixture of $\mathrm{PG}+\mathrm{TS}$ had no effect on the occurrence of neural/neuronal type cells, but a combination of $\mathrm{E} 2+\mathrm{PG}+\mathrm{TS}$ produced a small increase the subsequent day. No changes were observed in the vehicle-treated cells. Additional steroid treatment on Day 1 consisted of PG+TS. There was a marked conversion of fibroepithelial into neural/neuronal cell types in cultures pretreated with $\mathrm{E} 2+\mathrm{PG}+\mathrm{TS}$ or PG+TS the day before. The neural/neuronal type cells showed SSEA-4 expression in the porcine neuronal cell bodies and strong NCAM expression was detected in small stem-like cells. Stage-specific embryonic antigen-1 staining was seen in neuronal cell types but not in fibroepithelial cells. ${ }^{50}$ The presence of NSC with anchors after the combined steroid treatment in human ovarian stem cell cultures suggests that such stem cells could eventually be used in the systemic or topic autologous regenerative treatment of neuronal disorders in women. Once developed, numerous NSC are released in the culture medium and are easily collected without trypsinization. The human ovarian stem cultures can be readily obtained regardless of the patient's age. They could be frozen, re-cultivated, transdifferentiated into neural/neuronal type cells by sex steroid combination, and utilized for autologous stem cell therapy. In addition sex steroid mixtures can stimulate proliferation and differentiation of NSC in the CNS. They can also transdifferentiate potential sources of NSC such as in adult bone marrow and peripheral blood. These may be a natural source of NSC precursors, just as they are a source of hematologic and nonhematologic stem cell lineages. ${ }^{193,194}$ New NSC can differentiate from peripheral blood precursors in vitro, ${ }^{194}$ and possibly under the influ-

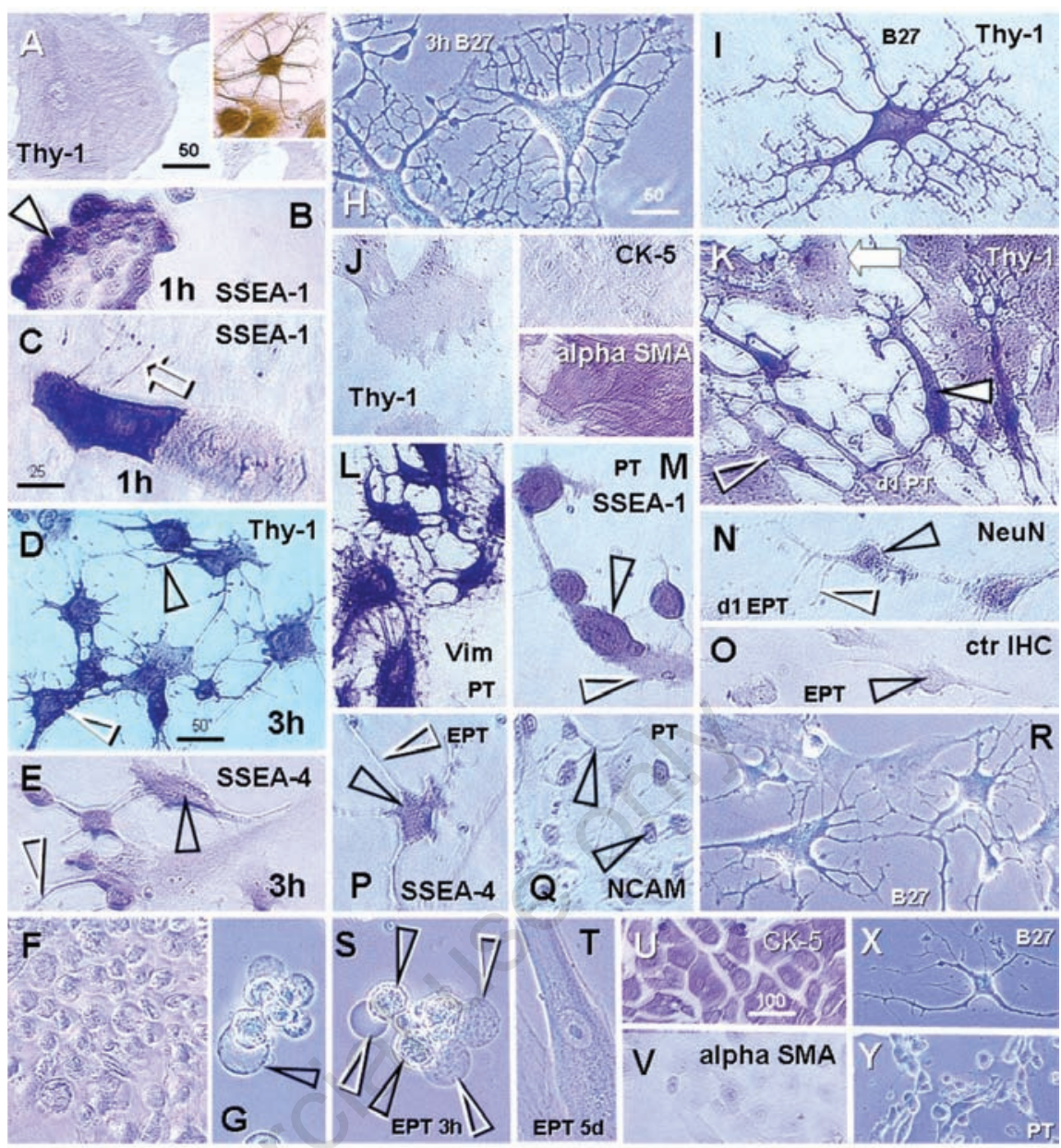

Figure 8. Ovarian, smooth muscle cell, and amniotic cultures after sex steroid combinations. Transdifferentiation of ovarian epithelial cells (A-I), vascular smooth muscle cells (J-T) and amniotic cells into neural and neuronal type cells (U-Y). A) Control ovarian epithelial cells show a low Thy-1 expression by some epithelial cells. Inset shows occasional spontaneous differentiation of neuronal type cell in ovarian culture. One day after E2 pretreatment and one hour after PG mixed with TS the ovarian cells dedifferentiated into small cells strongly expressing SSEA-1- arrowhead (B). C) Asymmetric division resulting in SSEA-1 ${ }^{+}$and SSEA-1- daughter cells. Arrow indicates stained early extensions. D) Three $b$ after treatment, the cells exhibited neuronal morphology with strong expression of Thy1 neuronal glycoconjugate in extensions (black arrowhead) and bodies (white arrowhead). E) Such cells also expressed SSEA-4 in their bodies (black arrowhead) but not extensions (white arrowhead). F) Putative stem cells were found to detach from the chamber bottoms floating in the center of the wells. G) These cells show bubble-like anchoring extensions (arrowhead). Ovarian epithelial cells $3 \boldsymbol{b}$ after B27 medium showed a direct transdifferentiation into neuronal type cells $(\mathrm{H})$ strongly expressing Thy-1 (I). Control vascular SMC shoved weak Thy 1 (J), no cytokeratin (CK-5, upper inset), and strong alpha SMA (lower inset). K) One day after PG+TS (PT) the cells exhibited enhanced Thy-1 expression and transition into neuronal type cells (open and solid arrowheads). L) Some such cultures consisted of neuronal type cells only. M) Staining for SSEA-1 revealed an asymmetric division (black $v s$ white arrowheads). N) An expression of neuronal nuclear antigen (NeuN) in the cell bodies 1 day after E2+PG+TS (EPT) treatment. O) Control IHC. P) Staining for SSEA-4 was similar to ovarian cultures (see panel E). Q) NCAM expression in cell bodies and extensions (arrowheads). R) Vascular SMC after $3 b$ in the B27 medium. S) Detached cells (black arrowheads) showing bubble-like anchoring extensions (white arrowheads). T) Reestablishment of the vascular smooth muscle cell type within five days. U) Culture of amniotic epithelial cells shoving CK-5 staining and no alpha SMA (V). X) Amniotic epithelial cells showed a transdifferentiation in B27 medium but responded poorly to the PT treatment ( $\mathrm{Y}$ vs $\mathrm{K}$ and $\mathrm{L}$ ). Numbers above bars indicate microns. A-G adapted from ${ }^{50}$ and $\mathrm{H}-\mathrm{V}$ adapted from ${ }^{10}$ with permission, ${ }^{\circ}$ Landes Bioscience; $\mathrm{X}$ and $\mathrm{Y}$ reprinted from ${ }^{10,12}$ with permission, ${ }^{\odot}$ Oxford: Wiley-Blackwell Scientific Publications. 
ence of sex steroids in vivo. Circulating NSC can home within the CNS, ${ }^{195}$ and could be stimulated to differentiate further by sequential steroid treatment, i.e. E2 followed by $\mathrm{PG}+\mathrm{TS} .{ }^{50}$

\section{Vascular smooth muscle cells show in vitro nuclear \\ reprogramming into neural and neuronal type cells and vascular smooth muscle stem cells}

We tested the effect of Neurobasal/B27 neuron culture medium with $2 \mathrm{mM}$ Glutamax (B27 medium) on cultured ovarian stem cells. ${ }^{10}$ B27 medium is utilized for the preservation of hippocampal neuronal cells in vitro since it substitutes the role of astrocytes, ${ }^{196}$ Within $3 \mathrm{~h}$, there was transdifferentiation of epithelial cells into interconnected neuronal type cells (Figure $8 \mathrm{H}$, phase contrast of living culture). Such cells strongly expressed Thy-1 neuronal glycoconjugate (Figure 8I), similar to cultures exposed to sex steroid combinations. These observations indicate that sex steroid combinations are as effective as B27 medium.

Subsequently, we cultured human vascular smooth muscle cells (SMC), non-epithelial mesenchymal cells known to express sex steroid receptors, ${ }^{197-199}$ to test them as a control cell type for their morphology and expression of NSC and neuronal markers. Unexpectedly, vascular SMC subjected to sex steroid combinations also transdifferentiated into neural type and differentiating neuronal type cells. ${ }^{10}$

These cultured vascular SMC exhibited weak expression of Thy-1differentiation protein (Figure 8J), characteristic of human vascular pericytes..$^{39}$ They did not express cytokeratin 5 (CK-5, upper inset), but strongly expressed alpha smooth muscle actin (alpha SMA, lower inset). The addition of individual sex steroids did not change SMC morphology (except PG - see below) or Thy-1 expression. However, one day after treatment with PG+TS (d1 PT, Figure 8K), transdifferentiation of SMC into neuronal type cells occurred, with strong Thy-1 expression (white arrowhead). Note also the enhanced Thy-1 expression in the remaining SMC (arrow, compare with Figure $8 \mathrm{~J})$. The open arrowhead indicates an SMC, which is already in the process of transdifferentiation into a neuronal cell.

The phenomenon which we labeled the brain in vitro feature ${ }^{50}$ is shown in Figure 8L, where all SMC transdifferentiate into interconnected neuronal type cells (vimentin stain). The emerging neural/neuronal type cells showed strong SSEA-1 expression. Figure $8 \mathrm{M}$ shows asymmetric division resulting in SSEA-1+ (black arrowhead) and SSEA-1 - (white arrowhead) daughters like seen in transdifferentiated OSE cultures (see Figure 8C). This indicates that neural cell precursors in ovarian and vascular SMC cultures are capable to pro- duce the differentiating neural cells and replicate themselves.

Neural nuclei protein (NeuN) expression in cultures after one day of E2+PG+TS (EPT, Figure $8 \mathrm{~N}$ ) treatment is associated with neuronal cell bodies (black arrowhead) but not extensions (white arrowhead). Control immunohistochemistry produced no staining of neuronal (arrowhead, Figure 80) or other cell types. Neuronal type cells showed stagespecific embryonic antigen 4 (SSEA-4, Figure 8P) in their bodies (black arrowhead) but not extensions (white arrowhead), like ovarian stem cell cultures (Figure 8E). Neuronal cell bodies and extensions expressed neural cell adhesion molecule (NCAM; arrowheads, Figure 8Q) characteristic of the later stages of neuronal differentiation. ${ }^{190}$ Neural cell adhesion molecule is used for the isolation of human embryonic stem cell-derived neurons. ${ }^{190}$

Utilization of B27 medium without steroids caused a fast (within $3 \mathrm{~h}$ ) transdifferentiation of SMC into neuronal type cells (Figure 8R, phase contrast of living culture) like in ovarian epithelial cell cultures (Figure 8H). These data clearly demonstrate that both the SMC and ovarian epithelial cells have the potential to transdifferentiate into neuronal type cells in media stimulating the preservation of neurons and neuronal differentiation of ESC. . $96,200^{2}$

Treatment with $\mathrm{E} 2+\mathrm{PG}+\mathrm{TS}$ caused a rapid (within $3 \mathrm{~h}$ ) conversion of SMC into stem type cells (black arrowheads, Figure 8S) exhibiting bubble-like anchors (white arrowheads) signaling capability of settlement. Within several days these cultures showed reestablishment of the vascular smooth muscle cell type (Figure $8 \mathrm{~T}$ ). This demonstrates that sex steroid combinations can cause transdifferentiation of SMC into neuronal and vascular smooth muscle stem cells.

As a positive control for CK-5 staining we used a culture of amniotic epithelial cells (Figure 8U) which did not express alpha SMA (negative control, Figure 8V)..$^{10}$ Amniotic cultures responded well by transdifferentiation into neuronal type cells after B27 treatment (Figure 8X), but not after sex steroid treatment (Figure $8 \mathrm{Y}$ ) - compare with Figure $8 \mathrm{~K} .{ }^{12}$

\section{$17 \beta$ estradiol in vascular smooth muscle cells cultures after testosterone, progesterone and testosterone + progesterone \\ treatment}

Our earlier study ${ }^{50}$ indicated that pretreatment with E2 is essential for the transdifferentiation of OSC and granulosa cells into NSC and neuronal type cells after PG+PT treatment. Some cultures were capable to transdifferentiate after $\mathrm{PG}+\mathrm{PT}$ alone, however, possibly due to the conversion of TS (and PG) by aromatase.
We examined the possibility that $\mathrm{PG}$, TS or both could be converted into E2 in vascular SMC cultures. The medium with 10\% FBS and spent control culture medium showed low E2 levels (E2 pg/mL 1050 \pm 150 and $1477 \pm 742$ SEM, respectively). Cultures after TS treatment showed significantly higher production of E2 $(22086 \pm 4650)$. PG pretreatment was even more effective $(71920 \pm 9090)$. The highest E2 levels were obtained by PG+TS pretreatment $(198202 \pm 40088) .^{10}$

These data confirm that E2 is produced in cultures pretreated with $\mathrm{PG}$ and TS. This explains the source of E2 from PG and TS conversion by vascular SMC. In vivo, advancing age is associated with diminution of circulating estrogens. However, in postmenopausal women and aging men the E2 continues to be produced in a number of extragonadal sites, including vascular SMC and numerous sites in the brain. ${ }^{201}$ Vascular SMC express aromatase and 17beta-hydroxysteroid dehydrogenase type I, which converts estrone, the major product of aromatase, to the more potent estrogen E2. ${ }^{202}$ Therefore, like in vitro, the PG and TS treatment in vivo may also be adequate to induce transdifferentiation of vascular SMC into vascular stem cells and neural/neuronal type cells in the sites, where this is needed.

\section{Combination of progesterone and} testosterone might be sufficient for the regenerative treatment

Interestingly, high circulating levels of a PG+TS combination are unlikely to occur naturally in either human females or males. $\mathrm{E} 2+\mathrm{PG}$ or $\mathrm{E} 2+\mathrm{TS}$ combinations are not capable of transdifferenting ovarian epithelial cells or vascular SMC into stem and neuronal type cells. However, such mixtures may arise locally, in the brain for example, as a combination of neurosteroids. ${ }^{188}$ Our observations ${ }^{10,50}$ suggest that either $\mathrm{E} 2+\mathrm{PG}+\mathrm{TS}$ treatment or $\mathrm{PG}+\mathrm{TS}$ treatment and $\mathrm{E} 2$ produced by targeted cells expressing aromatase+17beta-hydroxysteroid dehydrogenase type I are effective.

Studies suggest that large doses of progesterone for up to several days after injury limit CNS damage, reduce loss of neural tissue, and improve functional recovery. ${ }^{203}$ This is probably due to the combined effect of PG and locally produced E2. However, treatment with $\mathrm{PG}+\mathrm{TS}$ may enhance E2 production and induce transdifferentiation of vascular SMC into neural/neuronal type cells (PT, Figure 8K-M and $Q$ ). This could be even more effective in repairing CNS injuries.

\section{Vascular smooth muscle cells stem cells}

The ability of vascular SMC to transdifferentiate into neural and neuronal type cells is especially important because, unlike ovarian 
stem cells, as pericytes vascular SMC accompany all vessels, including the CNS microvasculature in both females and males. The combination of all three-sex steroids causes a rapid conversion of differentiated vascular SMC into stem type cells. These cells subsequently differentiate into mature vascular SMC. Vascular SMC, also known as pericytes, regulate endothelial cell properties and contribute to the stability and maintenance of blood vessels. They are likely to be pluripotential, serving as precursors for a variety of other cell types..$^{204}$ Hence vascular SMC accompany capillaries and post-capillary venules ${ }^{205}$ and function as mesenchymal stem cells in various tissues, including bone marrow stromal stem cells..$^{206-209}$

Pericytes represent a perivascular niche of mesenchymal stem cells residing in virtually all organs and tissues. They represent multipotent progenitor cells, which can give rise to mesenchymal and epithelial cells in vitro and in vivo. Their differentiation potential is related to their tissue of origin. All mesenchymal stem cell populations derived from distinct tissues, including bone marrow, spleen, muscle, aorta, vena cava, kidney, lung, liver, brain and thymus, show expression of alpha smooth muscle actin, suggesting their relationship to pericytes. ${ }^{210}$ Altogether, systemic or local (spinal cord injury) treatment with sex steroid combinations could stimulate transdifferentiation of resident vascular SMC to improve neurodegenerative, traumatic and ischemic neurological disorders and vascular diseases without utilization of in vitro developed stem cells.

The morphostatic maintenance of tissues declines with age, probably due to degenerative changes in the immune system. This is accompanied by an increased incidence of tissue dysfunctions such as type 2 diabetes mellitus associated with pericyte pathology ${ }^{211}$ and neurodegenerative diseases caused by apoptosis of neuronal type cells. ${ }^{212}$ One may expect that the regenerative approaches will be more likely successful in acute/traumatic injury treatment than in chronic tissue disorders, ${ }^{52}$ unless we are able to manage the attenuated or lost stop effect of MDC in specific tissues associated with aging (Figures $3 \mathrm{G}$ and orange arrowheads, in Figure 4).

\section{Cellular therapy without cells}

Within the field of regenerative medicine of neurodegenerative and traumatic neurologic disorders, there is considerable interest in cellular therapy such as engraftment of neural stem cells (NSC) in the CNS to induce neuronal renewal and repair. Neural stem cells can be isolated from the neonatal or adult CNS and propagated in vitro in the presence of mitogenic growth factors. ${ }^{213,214}$ Alternative sources of NSC include ESC, umbilical cord blood, amniotic epithelial cells, bone marrow stem cells, and mobilized peripheral blood CD133+ cells. ${ }^{193,194,215,216}$ After several passages, these cells can be transdifferentiated into NSC by fibroblast growth factor-1, 12-0-tetradecanoylphorbol-13-acetate (protein kinase C activator), isobutylmethylxanthine (a non-specific inhibitor of phosphodiesterases), and forskolin (protein kinase A activator), or alltrans-retinoic acid and 2-merkaptoethanol. ${ }^{217}$ These substances are not suitable for the treatment in vivo, however. An alternative to the utilization of organ/tissue specific stem cells for functional engraftment at particular sites (topic therapy) is an idea of systemic regenerative therapy or in situ regenerative treatment by common low molecular weight substances capable crossing a blood-tissue barrier, such as the blood-brain barrier. Our study has shown that sex steroid combinations (but not individual sex steroids) can directly transdifferentiate cultures of vascular SMC known to posses sex steroid receptors ${ }^{197-199}$ into neural and neuronal type cells. ${ }^{10}$ As we have noted, this is important since, unlike ovarian stem cells, the vascular SMC accompany as pericytes all vessels, including CNS microvasculature, as pericytes, and in both genders. We also observed that sex steroid combinations produce vascular SMC stem cells which differentiate within
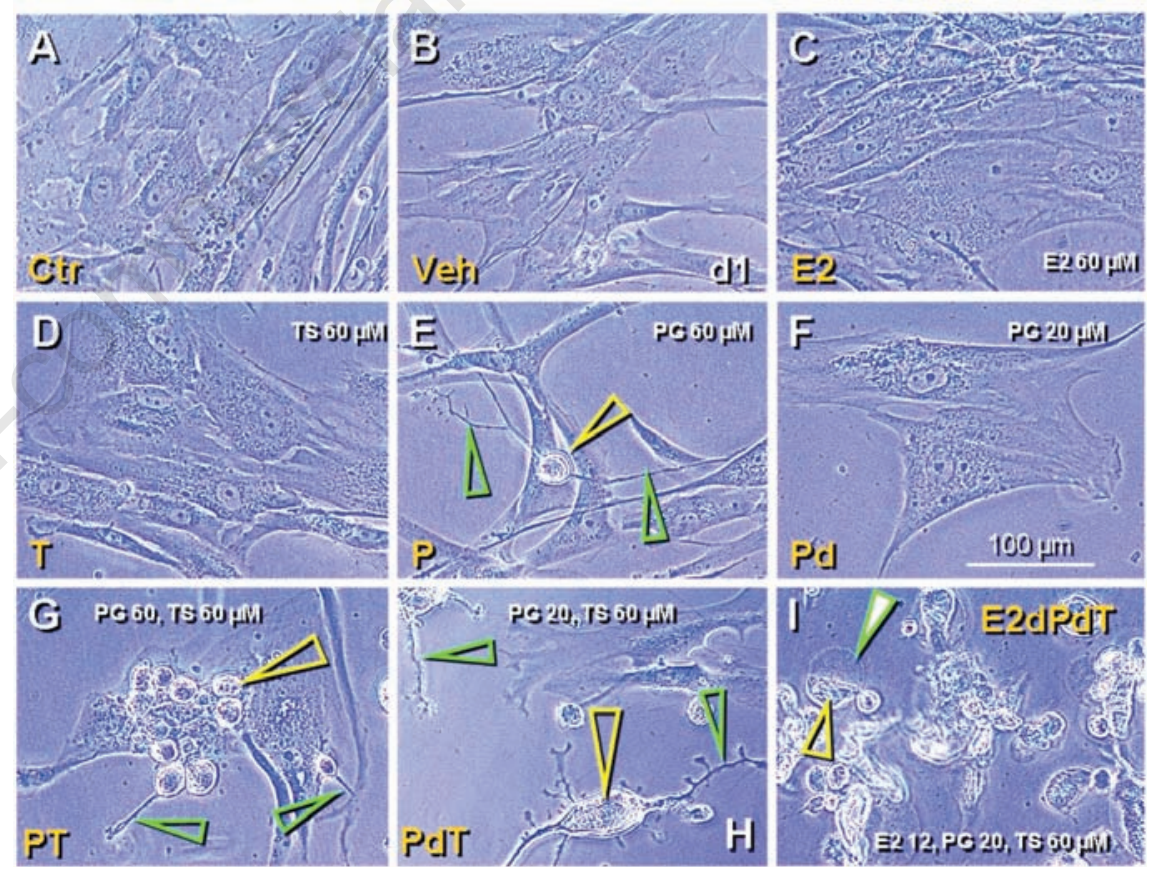

Figure 9. Sex steroid doses and combinations in vascular smooth muscle cell cultures. Control (A), vehicle (B), high estrogen (C), and high testosterone (D) treated cultures of vascular SMC showed no morphological changes. High progesterone treatment (E) was, however, associated with occasional neuronal type cells. This was not observed in cultures with diluted progesterone $(F)$. Cultures with high progesterone and high testosterone $(G)$ showed numerous neural type cells. Cultures with diluted progesterone and high testosterone $(\mathrm{H})$ showed direct nuclear transdifferentiation into neuronal type cells with branching extensions. Diluted estradiol and progesterone and high testosterone (I) exhibited formation of undifferentiated stem type cells. Open yellow arrowheads indicate neu$\mathrm{ral} /$ neuronal type cell bodies, green indicate extensions. Solid arrowhead in panel I indicates bubble-like anchor. Ctr, control; E2, estradiol; Ed, estradiol diluted; P, progesterone; Pd, progesterone diluted; PT, progesterone + Testosterone; Veh, vehicle. 
cultures (Figure 9A) and media with a vehicle alone (Figure 9B) showed no spontaneous transdifferentiation. Similar results were found with $60 \mu \mathrm{M}$ E2 (Figure 9C) and $60 \mu \mathrm{M}$ TS (Figure 9D) 1 day after the treatment. However, $60 \mu \mathrm{M}$ PG caused the occasional appearance of neuronal type cells (yellow arrowhead, Figure 9E) with their characteristic elongated early extensions (green arrowheads). This dose of PG corresponds to the concentration of $16 \mathrm{mg} / \mathrm{kg}$ found to reduce cell death, gliosis, and functional deficits after traumatic brain injury in rats. ${ }^{219} \mathrm{PG}$ may have some in vivo neuroprotective effect. Lower PG dose $(20 \mu \mathrm{M})$ had no in vitro effect on the appearance of neuronal type cells, however (Figure 9F).

When the $60 \mu \mathrm{M}$ PG was combined with 60 $\mu \mathrm{M}$ TS, numerous small neural stem cells (yellow arrowhead, Figure 9G) with short extensions (green arrowheads) appeared. This shows that numerous new neural stem cells can be generated by addition of high dose TS to high dose PG.

However when a lower concentration of PG $(20 \mu \mathrm{M})$ was used in cultures along with 60 $\mu \mathrm{M}$ TS, the vascular SMC showed direct nuclear transdifferentiation into differentiating neuronal type cells (yellow arrowhead, Figure 9H) with branching extensions (green arrowheads). It is important to note that the in vitro dose of diluted $\mathrm{PG}$ corresponds to the dose of PG suppositories (200 mg, used $2 \mathrm{x}$ daily) utilized in the prevention of miscarriage and preterm labor. ${ }^{220,221}$ The dose of TS is similar to intramuscular weekly injections of androgens (600 $\mathrm{mg})$ tested in human males. ${ }^{222,223}$ Hence, it should be safe to use daily doses of $400 \mathrm{mg}$ progesterone combined with weekly injections of $600 \mathrm{mg}$ testosterone in clinical trials to treat CNS dysfunctions.

When a low dose of E2 $(12 \mu \mathrm{M})$ was added to $20 \mu \mathrm{M}$ progesterone and $60 \mu \mathrm{M} \mathrm{TS}$, numerous stem cells (yellow arrowhead, Figure 9I) with bubble-like anchors (green arrowhead) developed in vascular SMC cultures. Since such cells within several days differentiate back into mature SMC (Figure $8 \mathrm{~S}$ and T), the treatment of vascular disorders with such a therapy is plausible. E2 $12 \mu \mathrm{M}$ in vitro corresponds $120 \mathrm{mg}$ in humans. Transdermal 17 beta-estradiol $50 \mathrm{mg}$ twice weekly has been used for hormone-replacement therapy. ${ }^{24}$

Pericytes regulate endothelial cell properties and contribute to the stability and maintenance of blood vessels. As we have noted, they have been proposed to be pluripotential and serve as precursors for a variety of other cell types, ${ }^{204}$ including cardiomyocytes. ${ }^{15}$ A combined treatment with all three sex steroids (400 mg of PG daily + $600 \mathrm{mg}$ of TS weekly + $50 \mathrm{mg}$ of E2 twice a week) for a period of two to four weeks may contribute to vascular regeneration after the occurrence of a stroke and regeneration of cardiomyocytes after myocardial infarction.

Taken together, in aging individuals or patients at risk of CNS or vascular and heart disorders, occasional treatment (once a year) with combined $\mathrm{PG}+\mathrm{TS}$ or $\mathrm{E} 2+\mathrm{PG}+\mathrm{TS}$ for a period of two to four weeks may have a preventive or regenerative effect. Since E2 can be locally derived from PG and TS, several doses of PG+TS combination (e.g. , $400 \mathrm{mg}$ of PG daily $+600 \mathrm{mg}$ of TS weekly for 2 to 4 weeks) could be sufficient for the CNS, vascular and heart regeneration. This could also be applicable in acute alterations such as spinal cord trauma, stroke, or myocardial infarction.

\section{The pros and cons of regenerative medicine}

The aim of what we term regenerative medicine is to replace altered tissue-specific cells with new cells originating either from stem cells or the reprogramming of committed differentiated cells from one lineage into another.

Therapies resulting in the transdifferentiation of autologous progenitor cells in situ by drugs or hormones crossing the blood barrier may be suitable approaches for treatment of neurological diseases and vascular disorders. This, theoretically, may be more successful in acute traumatic and ischemic disorders with preserved perivascular organ-specific SCN and TCS-mediated regulation of stem cell differentiation and preservation in a functional state. In chronic or degenerative diseases, however, the disorder may be associated with altered TCS-mediated function. As a consequence, attempts to regenerate organ function may not be as successful due to the lack of preservation of tissue-specific cells in the state required for proper tissue/organ function. It has been recently shown that aging is associated with the DNA hypermethylation of MDC. ${ }^{225}$ Such a situation can be improved by clinically achievable levels of 5-aza-2'-deoxycytidine (5-AZA$\mathrm{dC}$ ), a potent inhibitor of DNA methylation. ${ }^{226}$ Systemic transcriptional therapy could return the MDC into a normal state within specific tissues or cause a reversal of body aging. It may be more appropriate to influence the MDC locally, within an affected tissue, by in situ application of DNA methylation inhibitor, and to influence resident tissue-specific selfrenewing MDC in the basic TCU and cryptopatches. In diseases caused by a higher than required stop effect of MDC it could be possible to reverse type 1 diabetes in younger individuals, regenerate cirrhotic livers, and improve function of tissues affected by autoimmune and degenerative diseases with such an approach. Tissue affected by lower than required stop effect of MDC, such as muscular dystrophy, may however require the opposite approach, i.e., stimulation of DNA methylation in resident MDC. If we attain an ability to man- age the function of tissue-specific SCN and TCS-mediated functional preservation by MDC, we may be able to provide a treatment for early postnatal tissue disorders, improve regenerative medicine, and delay physical, mental, and hormonal aging.

\section{Conclusions}

Available data indicate that the morphostasis is a complex event requiring: i) Tissue renewal from stem cells, ii) Preservation of tissue-specific cells in the proper differentiated state, and iii) Regulation of tissue quantity. This can be executed by a TCS consisting of immune system related components, vascular pericytes, and autonomic innervation. Morphostasis is established epigenetically, during morphogenetic developmental immune adaptation, i.e. during the critical developmental period. Subsequently, the tissues are maintained in the state of differentiation reached during the adaptation by a stop effect of MDC. Alteration of tissue differentiation during the critical developmental period causes persistent alteration of tissue function. Morphostasis is altered with aging, due to degenerative changes of the immune system, resulting in the aging of individuals and an increased incidence of degenerative diseases. A promising aspect in regenerative medicine is a chemical approach, such as the combination of sex steroids stimulating endogenous stem cells for treatment of neuronal, vascular, and heart disorders. In aging individuals or patients at risk, occasional treatment with combined sex steroids for a period of 2 to 4 weeks may have a regenerative or preventive effect.

Regenerative medicine in affected patients, however, may be more successful in acute/traumatic disorders with intact morphostatic SCN as compared to the chronic and degenerative diseases caused by an altered SCN. Chronic degenerative diseases may be less responsive to regenerative medicine due to the defects in the TCS-mediated morphostasis, such as an alteration of the stop effect of MDC. The ability to manage the stop effect of MDC by transcriptional therapy may provide treatment for early postnatal tissue disorders, such as muscular dystrophy and type 1 diabetes, and delay physical, hormonal and mental aging of an individual, including the delay of menopause in women, sexual dysfunction in aging men, age associated high blood pressure, type 2 diabetes, and autoimmune diseases. Degenerative diseases may be associated with tissue cell apoptosis. If we are able to change morphostasis, we may disrupt apoptotic process of the cell and may improve our chances of treating chronic degenerative diseases. 


\section{References}

1. Rogers I. Transdifferentiation of endogenous cells: cell therapy without the cells. Cell Cycle 2009;8:4027-8.

2. Tesche LJ, Gerber DA. Tissue-derived stem and progenitor cells. Stem Cells Int 2010;2010:824876.

3. Choumerianou DM, Dimitriou H, Kalmanti M. Stem cells: promises versus limitations. Tissue Eng Part B Rev 2008;14:53-60.

4. Li Y, Cang M, Lee AS, et al. Reprogramming of sheep fibroblasts into pluripotency under a drug-inducible expression of mouse-derived defined factors. PLoS ONE 2011;6:e15947.

5. Suhr ST, Chang EA, Rodriguez RM, et al. Telomere dynamics in human cells reprogrammed to pluripotency. PLoS ONE 2009;4(:e8124.

6. Lister R, Pelizzola M, Kida YS, et al. Hotspots of aberrant epigenomic reprogramming in human induced pluripotent stem cells. Nature 2011;471:68-73.

7. Shen CN, Slack JM, Tosh D. Molecular basis of transdifferentiation of pancreas to liver. Nat Cell Biol 2000;2:879-87.

8. Ber I, Shternhall K, Perl S, et al. Functional, persistent, and extended liver to pancreas transdifferentiation. J Biol Chem 2003;278:31950-7.

9. Baeyens L, De BS, Lardon J, et al. In vitro generation of insulin-producing beta cells from adult exocrine pancreatic cells. Diabetologia 2005;48:49-57.

10. Bukovsky A. Sex steroid-mediated reprogramming of vascular smooth muscle cells to stem cells and neurons: Possible utilization of sex steroid combinations for regenerative treatment without utilization of in vitro developed stem cells. Cell Cycle 2009;8:4079-84.

11. Sarig R, Fuchs 0, Tencer L, et al. Cloned myogenic cells can transdifferentiate in vivo into neuron-like cells. PLoS ONE 2010;5:e8814.

12. Bukovsky A. Immune maintenance of self in morphostasis of distinct tissues, tumor growth, and regenerative medicine. Scand J Immunol 2011;73:159-89.

13. Caplan AI. Why are MSCs therapeutic? New data: new insight. J Pathol 2009;217: 318-24.

14. Davidoff MS, Middendorff R, Muller D, Holstein AF. The neuroendocrine Leydig cells and their stem cell progenitors, the pericytes. Adv Anat Embryol Cell Biol 2009;205:1-107.

15. Dohmann HF, Perin EC, Takiya CM, et al. Transendocardial autologous bone marrow mononuclear cell injection in ischemic heart failure: postmortem anatomicopathologic and immunohistochemical findings. Circulation 2005;112:521-6.

16. Augello A, Kurth TB, De BC. Mesenchymal stem cells: a perspective from in vitro cultures to in vivo migration and niches. Eur Cell Mater 2010;20:121-33.

17. Sato M, Suzuki S, Senoo H. Hepatic stellate cells: unique characteristics in cell biology and phenotype. Cell Struct Funct 2003;28:105-12.

18. Chow A, Lucas D, Hidalgo A, et al. Bone marrow CD169+ macrophages promote the retention of hematopoietic stem and progenitor cells in the mesenchymal stem cell niche. J Exp Med 2011;208:261-71.

19. Wiley LA, Rupp GR, Steinle JJ. Sympathetic innervation regulates basement membrane thickening and pericyte number in rat retina. Invest 0 phthalmol Vis Sci 2005; 46:744-8.

20. Wu DM, Kawamura H, Sakagami K, et al. Cholinergic regulation of pericyte-containing retinal microvessels. Am J Physiol Heart Circ Physiol 2003;284:H2083H2090.

21. Gaytan F, Bellido C, Morales C, et al. Effects of macrophage depletion at different times after treatment with ethylene dimethane sulfonate (EDS) on the regeneration of Leydig cells in the adult rat. $\mathrm{J}$ Androl 1994;15:558-64.

22. Seta N, Kuwana M. Derivation of multipotent progenitors from human circulating CD14+ monocytes. Exp Hematol 2010;38: 557-63.

23. Carrel A. Growth-promoting function of leukocytes. J Exp Med 1922;36:385-91.

24. Burwell RG. The role of lymphoid tissue in morphostasis. Lancet 1963;2:69-74.

25. Bukovsky A, Presl J, Krabec Z, Bednarik T. Ovarian function in adult rats treated with antithymocyte serum. Experientia 1977; 33:280-1.

26. Bukovsky A, Presl J. Ovarian function and the immune system. Med Hypotheses 1979;5:415-36.

27. Bukovsky A, Presl J, Holub M, et al. The localization of brain-thymus shared antigen (Thy-1) and thymosin 5 within the adult rat ovary. IRCS Med Sci 1982;10:6970.

28. Bukovsky A, Presl J, Zidovsky J, Mancal P. The localization of Thy-1.1, MRC OX 2 and Ia antigens in the rat ovary and fallopian tube. Immunology 1983;48:587-96.

29. Grim M, Bukovsky A. How closely are rat skeletal muscle development and regeneration processes related? Bibl Anat 1986; 29:154-72.

30. Bukovsky A, Michael SD, Presl J. Cellmediated and neural control of morphostasis. Med Hypotheses 1991;36:2618 .
31. Bukovsky A, Caudle MR, Keenan JA, et al. Quantitative evaluation of the cell cyclerelated retinoblastoma protein and localization of Thy-1 differentiation protein and macrophages during follicular development and atresia, and in human corpora lutea. Biol Reprod 1995;52:776-92.

32. Bukovsky A, Keenan JA, Caudle MR, et al. Immunohistochemical studies of the adult human ovary: possible contribution of immune and epithelial factors to folliculogenesis. Am J Reprod Immunol 1995;33: 323-40.

33. Bukovsky A, Caudle MR, Keenan JA, et al. Is corpus luteum regression an immunemediated event? Localization of immune system components, and luteinizing hormone receptor in human corpora lutea. Biol Reprod 1995;53:1373-84.

34. Bukovsky A, Caudle MR, Keenan JA, et al. Is irregular regression of corpora lutea in climacteric women caused by ageinduced alterations in the tissue control system? Am J Reprod Immunol 1996;36: $327-41$.

35. Bukovsky A, Ayala ME, Dominguez R, et al. Bone marrow derived cells and alternative pathways of oogenesis in adult rodents. Cell Cycle 2007;6:2306-9.

36. Bukovsky A, Caudle MR. Immune physiology of the mammalian ovary - a review. Am J Reprod Immunol 2008;59:12-26.

37. Bukovsky A, Caudle MR, Keenan JA, et al. Thy-1 differentiation protein and monocyte-derived cells during regeneration and aging of human placental villi. Am J Reprod Immunol 1999;42:135-52.

38. Bukovsky A, Caudle MR, Keenan JA. Dominant role of monocytes in control of tissue function and aging. Med Hypotheses 2000;55:337-47.

39. Bukovsky A, Caudle MR, Keenan JA, et al. Association of mesenchymal cells and immunoglobulins with differentiating epithelial cells. BMC Dev Biol 2001;1:11.

40. Bukovsky A. Mesenchymal cells in tissue homeostasis and cancer. Mod Asp Immunobiol 2000;1:43-7.

41. Bukovsky A, Caudle MR, Wimalasena J, et al. The role of the host-tumor interface and cell hybridization in invasive cancer. Med Hypotheses 2001;57:729-35.

42. Bukovsky A. Immune system involvement in the regulation of ovarian function and augmentation of cancer. Microsc Res Tech 2006;69:482-500.

43. Bukovsky A, Ayala ME, Dominguez R, et al. Postnatal androgenization induces premature aging of rat ovaries. Steroids 2000 Apr 1;65(4):190-205.

44. Bukovsky A, Ayala ME, Dominguez R, et al. Changes of ovarian interstitial cell hormone receptors and behavior of resident mesenchymal cells in developing 
and adult rats with steroid-induced sterility. Steroids 2002;67:277-89.

45. Bukovsky A, Caudle MR. Immunology: animal models. In: Ekerdt DJ, editor. Ency-clopedia of Aging. New York: Macmillan Reference USA; 2002. p. 691-5.

46. Bukovsky A. Oogenesis from human somatic stem cells and a role of immune adaptation in premature ovarian failure. Curr Stem Cell Res Ther 2006;1:289-303.

47. Bukovsky A, Caudle MR, Svetlikova M, Upadhyaya NB. Origin of germ cells and formation of new primary follicles in adult human ovaries. Reprod Biol Endocrinol 2004;2:20.

48. Bukovsky A, Caudle MR, Svetlikova M, et al. Oogenesis in adult mammals, including humans: a review. Endocrine 2005;26:301-16.

49. Bukovsky A. Cell commitment by asymmetric division and immune system involvement. Prog Mol Subcell Biol 2007;45:179-204.

50. Bukovsky A, Caudle MR, Svetlikova M. Steroid-mediated differentiation of neu$\mathrm{ral} /$ neuronal cells from epithelial ovarian precursors in vitro. Cell Cycle 2008;7:3577-83.

51. Bukovsky A, Caudle MR, Virant-Klun I, et al. Immune physiology and oogenesis in fetal and adult humans, ovarian infertility, and totipotency of adult ovarian stem cells. Birth Defects Res C Embryo Today 2009;87:64-89.

52. Bukovsky A, Caudle MR, Carson RJ, et al. Immune physiology in tissue regeneration and aging, tumor growth, and regenerative medicine. Aging 2009;1:157-81.

53. Bukovsky A. How Can Female Germline Stem Cells Contribute to the Physiological Neo-Oogenesis in Mammals and Why Menopause Occurs? Microsc Microanal 2011;17:498-505.

54. Frisancho AR. Developmental adaptation: where we go from here. Am J Hum Biol 2009;21:694-703.

55. Joss-Moore LA, Metcalfe DB, Albertine $\mathrm{KH}$, et al. Epigenetics and fetal adaptation to perinatal events: diversity through fidelity. J Anim Sci 2010;88(13 Suppl):E216-E222.

56. Cuk M, Radosevic-Stasic B, Milin C, et al. Lymphoid system as a regulator of morphostasis and hormonal regulation of these functions. Ann N Y Acad Sci 1987; 496:104-7.

57. Bockman DE, Kirby ML. Dependence of thymus development on derivatives of the neural crest. Science 1984;223:498-500.

58. Bockman DE. Development of the thymus. Microsc Res Tech 1997;38:209-15.

59. Jung J, Mysliwiec MR, Lee Y. Roles of JUMONJI in mouse embryonic development. Dev Dyn 2005;232:21-32.
60. Sprent J, Cho JH. Self/non-self discrimination and the problem of keeping $\mathrm{T}$ cells alive. Immunol Cell Biol 2008;86:54-6.

61. Giese T, Sommerer C, Zeier M, Meuer S. Approaches towards individualized immu-ne intervention. Dig Dis 2010;28:45-50.

62. Beagley KW, Husband AJ. Intraepithelial lymphocytes: origins, distribution, and function. Crit Rev Immunol 1998;18:23754.

63. Kroemer G, Cuende E, Martinez C. Compartmentalization of the peripheral immune system. Adv Immunol 1993;53: 157-216.

64. Kawaguchi M, Nanno M, Umesaki Y, et al. Cytolytic activity of intestinal intraepithelial lymphocytes in germ-free mice is strain dependent and determined by $\mathrm{T}$ cells expressing gamma delta T-cell antigen receptors. Proc Natl Acad Sci U S A 1993;90:8591-4.

65. Peters H, McNatty KP. The Ovary. A Correlation of Structure and Function in Mammals. Berkeley and Los Angeles, California: University of California Press; 1980.

66. Terada T, Matsunaga Y. S-100-positive nerve fibers in hepatocellular carcinoma and intrahepatic cholangiocarcinoma: an immunohistochemical study. Pathol Int 2001;51:89-93.

67. Williams AF. A year in the life of the immunoglobulin superfamily. Immunol Today 1987;8:298-303.

68. Hogaboam CM, Steinhauser ML, Chensue SW, Kunkel SL. Novel roles for chemokines and fibroblasts in interstitial fibrosis. Kidney Int 1998;54:2152-9.

69. Chung AS, Kao WJ. Fibroblasts regulate monocyte response to ECM-derived matrix: the effects on monocyte adhesion and the production of inflammatory, matrix remodeling, and growth factor proteins. J Biomed Mater Res A 2009;89:84153.

70. Vasselon T, Hailman E, Thieringer R, Detmers PA. Internalization of monomeric lipopolysaccharide occurs after transfer out of cell surface CD14. J Exp Med 1999;190:509-21.

71. Edelman GM. Morphoregulatory molecules. Biochemistry 1988;27:3533-43.

72. Schultz G, Rotatori DS, Clark W. EGF and TGF-alpha in wound healing and repair. J Cell Biochem 1991;45:346-52.

73. Hom DB, Maisel RH. Angiogenic growth factors: their effects and potential in soft tissue wound healing. Ann Otol Rhinol Laryngol 1992;101:349-54.

74. Yanagita K, Matsumoto K, Sekiguchi K, et al. Hepatocyte growth factor may act as a pulmotrophic factor on lung regeneration after acute lung injury. J Biol Chem 1993;
268:21212-7.

75. Gherardi E, Sharpe M, Lane K, et al. Hepatocyte growth factor/scatter factor (HGF/SF), the c-met receptor and the behavior of epithelial cells. Symp Soc Exp Biol 1993;47:163-81.

76. Kovacs EJ, DiPietro LA. Fibrogenic cytokines and connective tissue production. FASEB J 1994;8:854-61.

77. Gu Q, Wang D, Cui C, et al. Effects of radiation on wound healing. J Environ Pathol Toxicol Oncol 1998;17:117-23.

78. Carmeliet P, Collen D. Molecular analysis of blood vessel formation and disease. Am J Physiol 1997;273:H2091-H2104.

79. Lotan M, Schwartz M. Cross talk between the immune system and the nervous system in response to injury: implications for regeneration. FASEB J 1994;8:1026-33.

80. Viebahn CS, Benseler V, Holz LE, et al. Invading macrophages play a major role in the liver progenitor cell response to chronic liver injury. $\mathrm{J}$ Hepatol 2010;53:500-7.

81. Williams SE, Beronja S, Pasolli HA, Fuchs E. Asymmetric cell divisions promote Notch-dependent epidermal differentiation. Nature 2011;470:353-8.

82. Jahnsen FL, Gran E, Haye R, Brandtzaeg P. Human nasal mucosa contains antigenpresenting cells of strikingly different functional phenotypes. Am J Respir Cell Mol Biol 2004;30:31-7.

83. Chan A, Rubin J, Bottaro D, et al. Isoforms of human HGF and their biological activities. EXS 1993;65:67-79.

84. Weidner KM, Hartmann G, Naldini L, et al. Molecular characteristics of HGF-SF and its role in cell motility and invasion. EXS 1993;65:311-28.

85. Tajima H, Matsumoto K, Nakamura T. Regulation of cell growth and motility by hepatocyte growth factor and receptor expression in various cell species. Exp Cell Res 1992;202:423-31.

86. Tsuka H, Mori H, Li B, et al. Enhanced hepatocyte growth factor level in human prostate cancer treated with endocrine therapy. Int J Oncol 1998;13:169-76.

87. Jiang WG, Hallett MB, Puntis MC. Hepatocyte growth factor/scatter factor, liver regeneration and cancer metastasis. Br J Surg 1993;80:1368-73.

88. Conway K, Price P, Harding KG, Jiang WG. The molecular and clinical impact of hepatocyte growth factor, its receptor, activators, and inhibitors in wound healing. Wound Repair Regen 2006;14:2-10.

89. Cohen FE, Novotny J, Sternberg MJE, et al. Analysis of structural similarities between brain Thy-1 antigen and immunoglobulin domains. Biochem J 1981;195:31-40.

90. Williams AF, Barclay AN. The immuno- 
globulin superfamily--domains for cell surface recognition. Annu Rev Immunol 1988;6: 381-405.

91. Bukovsky A, Caudle MR, Keenan JA. Regulation of ovarian function by immune system components: the tissue control system (TCS). In: Motta PM, editor. Microsco-py of Reproduction and Development: A Dynamic Approach. Roma: Antonio Delfino Editore; 1997. p. 79-89.

92. Perreault $\mathrm{C}$. The Origin and Role of MHC Class I-Associated Self-Peptides. Prog Mol Biol Transl Sci 2010;92C:41-60.

93. Barclay AN, Letarte-Muirhead M, Williams AF, Faulkes RA. Chemical characterization of the Thy-1 glycoproteins from the membranes of rat thymocytes and brain. Nature 1976;267:563-7.

94. Dwek RA, Ashford DA, Edge CJ, et al. Glycosylation of CD4 and Thy-1. Philos Trans R Soc Lond B Biol Sci 1993;342:4350.

95. Sato Y, Tsukada K, liai T, et al. Activation of extrathymic $\mathrm{T}$ cells in the liver during liver regeneration following partial hepatectomy. Immunology 1993;78:86-91.

96. Nonaka $\mathrm{S}$, Naito $\mathrm{T}$, Chen $\mathrm{H}$, et al. Intestinal gamma delta T cells develop in mice lacking thymus, all lymph nodes, Peyer's patches, and isolated lymphoid follicles. J Immunol 2005;174:1906-12.

97. Oida T, Suzuki K, Nanno M, et al. Role of gut cryptopatches in early extrathymic maturation of intestinal intraepithelial $\mathrm{T}$ cells. J Immunol 2000;164:3616-26.

98. Barrett TA, Gajewski TF, Danielpour D, et al. Differential function of intestinal intraepithelial lymphocyte subsets. J Immunol 1992;149:1124-30.

99. Eberl G. Inducible lymphoid tissues in the adult gut: recapitulation of a fetal developmental pathway? Nat Rev Immunol 2005;5:413-20.

100. Mathe G. Immunity aging. I. The chronic perduration of the thymus acute involution at puberty? Or the participation of the lymphoid organs and cells in fatal physiologic decline? Biomed Pharmacother 1997;51:49-57.

101. McDonald KG, Leach MR, Huang C, et al. Aging impacts isolated lymphoid follicle development and function. Immun Ageing 2011;8:1.

102. Pashov A, Kenderov A, Kyurkchiev S, et al. Autoantibodies to heat shock protein 90 in the human natural antibody repertoire. Int Immunol 2002;14:453-61.

103. Avrameas S. Natural autoantibodies: from 'horror autotoxicus' to 'gnothi seauton'. Immunol Today 1991;12:154-9.

104. Marchalonis JJ, Hohman VS, Thomas C, Schluter SF. Antibody production in sharks and humans: a role for natural antibodies. Dev Comp Immunol 1993;17: 41-53.

105. Serre G, Vincent C, Viraben R, Soleilhavoup JP. Natural IgM and IgG autoantibodies to epidermal keratins in normal human sera. I: ELISA-titration, immunofluorescence study. J Invest Dermatol 1987;88:21-7.

106. Fleming SD, Tsokos GC. Complement, natural antibodies, autoantibodies and tissue injury. Autoimmun Rev 2006;5:8992.

107. Boes M. Role of natural and immune IgM antibodies in immune responses. Mol Immunol 2000;37:1141-9.

108. Underwood JR, McCall A, Csar XF. Naturally-occurring anti-thymocyte autoantibody which identifies a restricted CD4+CD8+CD3-/lo/int thymocyte subpopulation exhibits extensive polyspecificity. Thymus 1996;24:61-88.

109. Senda S, Cheng E, Kawanishi H. IgG in murine intestinal secretions. Aging effect and possible physiological role. Scand J Immunol 1989;29:41-7.

110. Johansen FE, Pekna M, Norderhaug IN, et al. Absence of epithelial immunoglobulin A transport, with increased mucosal leakiness, in polymeric immunoglobulin receptor/secretory component-deficient mice. J Exp Med 1999;190:915-22.

111. Naito M. Macrophage differentiation and function in health and disease. Pathol Int 2008;58:143-55.

112. Kelemen E, Janossa M. Macrophages are the first differentiated blood cells formed in human embryonic liver. Exp Hematol 1980;8:996-1000.

113. Korzhevskii DE. Macrophages of the human embryonic telencephalic choroid plexus. Neurosci Behav Physiol 2002;32:11-3.

114. Williams AF, Tse AG, Gagnon J. Squid glycoproteins with structural similarities to Thy- 1 and Ly- 6 antigens. Immunogenetics 1988;27:265-72.

115. Engelmann P, Cooper EL, Nemeth P. Anticipating innate immunity without a Toll. Mol Immunol 2005;42:931-42.

116. Chappell JC, Bautch VL. Vascular development: genetic mechanisms and links to vascular disease. Curr Top Dev Biol 2010; 90:43-72.

117. Vallejo AN, Miller NW, Clem LW. Phylogeny of immune recognition: role of alloantigens in antigen presentation in channel catfish immune responses. Immunology 1991;74:165-8.

118. Miller NW, Deuter A, Clem LW. Phylogeny of lymphocyte heterogeneity: the cellular requirements for the mixed leucocyte reaction with channel catfish. Immu-nology 1986;59:123-8.

119. Klein J. Immunology: The Science of Self-
Nonself Discrimination. New York: John Wiley and Sons, Inc.; 1982.

120. Yerkovich ST, Wikstrom ME, Suriyaarachchi D, et al. Postnatal development of monocyte cytokine responses to bacterial lipopolysaccharide. Pediatr Res 2007;62:547-52.

121. Silverstein AM. From the forehead of Zeus: the ontogeny of the immune response. Eye 1995;9:147-51.

122. Steinman RM, Banchereau J. Taking dendritic cells into medicine. Nature 2007; 449:419-26.

123. Kumar M, Cohen D, Eisdorfer C. Serum IgG brain reactive antibodies in Alzheimer disease and Down syndrome. Alzheimer Dis Assoc Disord 1988;2:50-5.

124. Alafuzoff I, Adolfsson R, Grundke-Iqbal I, Winblad B. Perivascular deposits of serum proteins in cerebral cortex in vascular dementia. Acta Neuropathol 1985; 66:292-8.

125. Wisniewski HM, Kozlowski PB. Evidence for blood-brain barrier changes in senile dementia of the Alzheimer type (SDAT). Ann N Y Acad Sci 1982;396:119-29.

126. Ruwhof C, Canning MO, Grotenhuis K, et al. Accessory cells with a veiled morphology and movement pattern generated from monocytes after avoidance of plastic adherence and of NADPH oxidase activation. A comparison with GM-CSF/IL-4induced monocyte-derived dendritic cells. Immunobiology 2002;205:247-66.

127. Ruwhof C, Canning MO, Grotenhuis K, et al. Accessory cells with a veiled morphology and movement pattern generated from monocytes after avoidance of plastic adherence and of NADPH oxidase activation. A comparison with GM-CSF/LL-4induced monocyte-derived dendritic cells. Immunobiology 2002;205:247-66.

128. Kushwah R, Hu J. Dendritic cell apoptosis: regulation of tolerance versus immunity. J Immunol 2010;185:795-802.

129. Naito M, Umeda S, Yamamoto T, et al. Development, differentiation, and phenotypic heterogeneity of murine tissue macrophages. J Leukoc Biol 1996;59:1338.

130. Tacke F, Randolph GJ. Migratory fate and differentiation of blood monocyte subsets. Immunobiology 2006;211:609-18.

131. Summerfield A, McCullough KC. The porcine dendritic cell family. Dev Comp Immunol 2009;33:299-309.

132. van der Laak JA, de Bie LM, de LH, et al. The effect of Replens on vaginal cytology in the treatment of postmenopausal atrophy: cytomorphology versus computerised cytometry. J Clin Pathol 2002;55:446-51.

133. Sato T, Fukazawa Y, Kojima H, et al. Apoptotic cell death during the estrous cycle in the rat uterus and vagina. Anat 
$\operatorname{Rec} 1997 ; 248: 76-83$.

134. Takasugi N, Bern HA, DEOME KB. Persistent vaginal cornification in mice. Science 1962;138:438-9.

135. Suzuki A, Watanabe H, Mizutani T, et al. Global gene expression in mouse vaginae exposed to diethylstilbestrol at different ages. Exp Biol Med (Maywood) 2006;231: $632-40$.

136. Verloop J, van Leeuwen FE, Helmerhorst $\mathrm{TJ}$, et al. Cancer risk in DES daughters. Cancer Causes Control 2010;21:999-1007.

137. Daar AS, Fabre JW. Organ-specific IgM autoantibodies to liver, heart and brain in man: generalized occurrence and possible functional significance in normal individuals, and studies in patients with multiple sclerosis. Clin Exp Immunol 1981;45:3747.

138. Ransohoff RM. Microglia and monocytes: 'tis plain the twain meet in the brain. Nat Neurosci 2011;14:1098-100.

139. German DC, Eagar T, Sonsalla PK. Parkinson's Disease: A Role for the Immune System. Curr Mol Pharmacol 2011 Jun 15. [Epub ahead of print].

140. Mohajeri M, Farazmand A, Mohyeddin BM, et al. FOXP3 Gene Expression in Multiple Sclerosis Patients Pre- and Post Mesenchymal Stem Cell Therapy. Iran J Allergy Asthma Immunol 2011;10:155-61.

141. Cebra JJ, Periwal SB, Lee G, et al. Development and maintenance of the gut-associated lymphoid tissue (GALT): the roles of enteric bacteria and viruses. Dev Immunol 1998;6:13-8.

142. Fries PN, Griebel PJ. Mucosal dendritic cell diversity in the gastrointestinal tract. Cell Tissue Res 2010;343:33-41.

143. Agarwal S, Cunningham-Rundles C. Autoimmunity in common variable immunodeficiency. Curr Allergy Asthma Rep 2009;9:347-52.

144. Lerner A. New therapeutic strategies for celiac disease. Autoimmun Rev 2010; 9:144-7.

145. Fuchs E, Raghavan S. Getting under the skin of epidermal morphogenesis. Nat Rev Genet 2002;3:199-209.

146. Mack JA, Anand S, Maytin EV. Proliferation and cornification during development of the mammalian epidermis. Birth Defects Res C Embryo Today 2005;75:314-29.

147. Haake AR, Cooklis M. Incomplete differentiation of fetal keratinocytes in the skin equivalent leads to the default pathway of apoptosis. Exp Cell Res 1997;231:83-95.

148. Gunathilake R, Schmuth M, Scharschmidt TC, et al. Epidermal barrier dysfunction in non-atopic HIV: evidence for an "insideto-outside" pathogenesis. J Invest Dermatol 2010;130:1185-8.

149. Emery AE. The muscular dystrophies.
Lancet 2002;359:687-95.

150. Dellavalle A, Sampaolesi M, Tonlorenzi R, et al. Pericytes of human skeletal muscle are myogenic precursors distinct from satellite cells. Nat Cell Biol 2007;9:255-67.

151. Biel M, Wascholowski V, Giannis A. Epigenetics--an epicenter of gene regulation: histones and histone-modifying enzymes. Angew Chem Int Ed Engl 2005; 44:3186-216.

152. Plagemann A, Harder T, Brunn M, et al. Hypothalamic proopiomelanocortin promoter methylation becomes altered by early overfeeding: an epigenetic model of obesity and the metabolic syndrome. J Physiol 2009;587:4963-76.

153. Miao F, Gonzalo IG, Lanting L, Natarajan R. In vivo chromatin remodeling events leading to inflammatory gene transcription under diabetic conditions. J Biol Chem 2004;279:18091-7.

154. Miao F, Wu X, Zhang L, et al. Genomewide analysis of histone lysine methylation variations caused by diabetic conditions in human monocytes. J Biol Chem 2007;282:13854-63.

155. Miao F, Smith DD, Zhang L, et al. Lymphocytes from patients with type 1 diabetes display a distinct profile of chromatin histone $\mathrm{H} 3$ lysine 9 dimethylation: an epigenetic study in diabetes. Diabetes 2008;57:3189-98.

156. Deshpande RR, Chapman JC, Michael SD. The anovulation in female mice resulting from postnatal injections of estrogen is correlated with altered levels of CD8+ lymphocytes. Am J Reprod Immunol 1997; 38:114-20.

157. Weetman AP. Immunity, thyroid function and pregnancy: molecular mechanisms. Nat Rev Endocrinol 2010;6:311-8.

158. Owen RD. Immunogenetic consequences of vascular anastomosis between bovine twins. Science 1945;102:400-1.

159. Dunsford I, Bowley CC, Hutchison AM, et al. A human blood-group chimera. Br Med J 1953;2:81.

160. Hasek M. Parabiosis of birds during embryonic development. Cesk Biol 1953; 2:265-70.

161. Billingham RE, Brent L, Medawar PB. Actively acquired tolerance of foreign cells. Nature 1953;172:603-6.

162. Deshpande RR, Chapman JC, Michael SD. The anovulation in female mice resulting from postnatal injections of estrogen is correlated with altered levels of CD8+ lymphocytes. Am J Reprod Immunol 1997; 38:114-20.

163. Rognum T0, Thrane S, Stoltenberg L, et al. Development of intestinal mucosal immunity in fetal life and the first postnatal months. Pediatr Res 1992;32:145-9.

164. Balogh P, Aydar Y, Tew JG, Szakal AK.
Ontogeny of the follicular dendritic cell phenotype and function in the postnatal murine spleen. Cell Immunol 2001; 214:45-53.

165. Hansen PE, Ballesteros MC, Soila K, et al. MR imaging of the developing human brain. Part 1. Prenatal development. Radiographics 1993;13:21-36.

166. Lowery LA, Sive H. Totally tubular: the mystery behind function and origin of the brain ventricular system. Bioessays 2009;31:446-58.

167. McGonigal G, Thomas B, McQuade C, et al. Epidemiology of Alzheimer's presenile dementia in Scotland, 1974-88. BMJ 1993;306:680-3.

168. Lathe R. Hormones and the hippocampus. J Endocrinol 2001;169:205-31.

169. Humphrey T. The development of the human hippocampal fissure. J Anat 1967;101:655-76.

170. Hoek A, van Kasteren Y, de HaanMeulman M, et al. Dysfunction of monocytes and dendritic cells in patients with premature ovarian failure. Am J Reprod Immunol 1993;30:207-17.

171. Espey LL. Ovulation as an inflammatory reaction--a hypothesis. Biol Reprod 1980;22:73-106.

172. Broadus J, Doe CQ. Extrinsic cues, intrinsic cues and microfilaments regulate asymmetric protein localization in Drosophila neuroblasts. Curr Biol 1997;7:827-35.

173. Jan YN, Jan LY. Polarity in cell division: what frames the fearful asymmetry? Cell 2000;100:599-602.

174. Lear BC, Skeath JB, Patel NH. Neural cell fate in rcal and cycA mutants: the roles of intrinsic and extrinsic factors in asymmetric division in the Drosophila central nervous system. Mech Dev 1999; 88:20719.

175. Seery JP, Watt FM. Asymmetric stem-cell divisions define the architecture of human oesophageal epithelium. Curr Biol 2000;10:1447-50.

176. Stofanko M, Kwon SY, Badenhorst P. Lineage tracing of lamellocytes demonstrates Drosophila macrophage plasticity. PLoS ONE 2010;5:e14051.

177. Dyce PW, Zhu H, Craig J, Li J. Stem cells with multilineage potential derived from porcine skin. Biochem Biophys Res Commun 2004;316:651-8.

178. Dyce PW, Wen L, Li J. In vitro germline potential of stem cells derived from fetal porcine skin. Nat Cell Biol 2006;8:384-90.

179. Dyce PW, Li J. From skin cells to ovarian follicles? Cell Cycle 2006;5:1371-5.

180. Dyce PW, Shen W, Huynh E, et al. Analysis of Oocyte-Like Cells Differen-tiated from Porcine Fetal Skin-Derived Stem Cells. Stem Cells Dev 2011;20:809-19. 
181. Alberts B, Bray D, Lewis J, et al. Molecular Biology of the Cell. Third ed. New York: Garland Publishing, Inc.; 1994.

182. Bukovsky A, Svetlikova M, Caudle MR. Oogenesis in cultures derived from adult human ovaries. Reprod Biol Endocrinol 2005;3:17.

183. Bukovsky A, Virant-Klun I. Adult stem cells in the human ovary. In: Simon C, Pellicer A, editors. Stem Cells in Reproductive Medicine: Basic Science \& Therapeutic Potential. London: Informa Healthcare; 2006. p. 53-69.

184. Virant-Klun I, Zech N, Rozman P, et al. Putative stem cells with an embryonic character isolated from the ovarian surface epithelium of women with no naturally present follicles and oocytes. Differentiation 2008;76:843-56.

185. Virant-Klun I, Rozman P, Cvjeticanin B, et al. Parthenogenetic Embryo-Like Structures in the Human Ovarian Surface Epithelium Cell Culture in Postmenopausal Women with No Naturally Present Follicles and Oocytes. Stem Cells Dev 2009;18:137-50.

186. Santos TA, Dias C, Henriques P, et al. Cytogenetic analysis of spontaneously activated noninseminated oocytes and parthenogenetically activated failed fertilized human oocytes-implications for the use of primate parthenotes for stem cell production. J Assist Reprod Genet 2003;20:122-30.

187. Motta PM, Makabe S, Naguro T, Correr S. Oocyte follicle cells association during development of human ovarian follicle. A study by high resolution scanning and transmission electron microscopy. Arch Histol Cytol 1994;57:369-94.

188. Fuller SJ, Tan RS, Martins RN. Androgens in the etiology of Alzheimer's disease in aging men and possible therapeutic interventions. J Alzheimers Dis 2007;12:12942.

189. Westberg L, Eriksson E. Sex steroid-related candidate genes in psychiatric disorders. J Psychiatry Neurosci 2008;33:31930.

190. Pruszak J, Sonntag KC, Aung MH, et al. Markers and methods for cell sorting of human embryonic stem cell-derived neural cell populations. Stem Cells 2007;25:2257-68.

191. Rosen CL, Lisanti MP, Salzer JL. Expression of unique sets of GPI-linked proteins by different primary neurons in vitro. J Cell Biol 1992;117:617-27.

192. Barraud P, Stott S, Mollgard K, et al. In vitro characterization of a human neural progenitor cell coexpressing SSEA4 and CD133. J Neurosci Res 2007;85:250-9.

193. Song S, Sanchez-Ramos J. Preparation of neural progenitors from bone marrow and umbilical cord blood. Methods Mol Biol 2002;198:79-88.

194. Kuci S, Kuci Z, Schmid S, et al. Efficient in vitro generation of adult multipotent cells from mobilized peripheral blood CD133+ cells. Cell Prolif 2008;41:12-27.

195. Corti S, Locatelli F, Papadimitriou D, et al. Multipotentiality, homing properties, and pyramidal neurogenesis of CNS-derived LeX(ssea-1)+/CXCR4+ stem cells. FASEB J 2005;19:1860-2.

196. Brewer GJ, Torricelli JR, Evege EK, Price PJ. Optimized survival of hippocampal neurons in B27-supplemented Neurobasal, a new serum-free medium combination. J Neurosci Res 1993;35:567-76.

197. Hodges YK, Richer JK, Horwitz KB, Horwitz LD. Variant estrogen and progesterone receptor messages in human vascular smooth muscle. Circulation 1999;99:2688-93.

198. Hodges YK, Tung L, Yan XD, et al. Estrogen receptors alpha and beta: prevalence of estrogen receptor beta mRNA in human vascular smooth muscle and transcriptional effects. Circulation 2000;101:1792-8.

199. Ma R, Wu S, Lin Q. Homologous up-regulation of androgen receptor expression by androgen in vascular smooth muscle cells. Horm Res 2005;63:6-14.

200. Shin S, Mitalipova M, Noggle S, et al. Long-term proliferation of human embryonic stem cell-derived neuroepithelial cells using defined adherent culture conditions. Stem Cells 2006;24:125-38.

201. Simpson ER. Aromatization of androgens in women: current concepts and findings. Fertil Steril 2002;77 Suppl 4:S6-10.

202. Murakami H, Harada N, Sasano H. Aromatase in atherosclerotic lesions of human aorta. J Steroid Biochem Mol Biol 2001;79:67-74.

203. Wang JM, Liu L, Irwin RW, et al. Regenerative potential of allopregnanolone. Brain Res Rev 2008;57:398-409.

204. Thomas WE. Brain macrophages: on the role of pericytes and perivascular cells. Brain Res Rev 1999;31:42-57.

205. Shepro D, Morel NM. Pericyte physiology. FASEB J 1993;7:1031-8.

206. Doherty MJ, Ashton BA, Walsh S, et al. Vascular pericytes express osteogenic potential in vitro and in vivo. $\mathrm{J}$ Bone Miner Res 1998;13:828-38.

207. Bianco P, Riminucci M, Gronthos S, Robey PG. Bone marrow stromal stem cells: nature, biology, and potential applications. Stem Cells 2001;19:180-92.

208. Shi S, Gronthos S. Perivascular niche of postnatal mesenchymal stem cells in human bone marrow and dental pulp. J Bone Miner Res 2003;18:696-704.

209. Farrington-Rock C, Crofts NJ, Doherty
MJ, et al. Chondrogenic and adipogenic potential of microvascular pericytes. Circulation 2004;110:2226-32.

210. da Silva ML, Chagastelles PC, Nardi NB. Mesenchymal stem cells reside in virtually all post-natal organs and tissues. J Cell Sci 2006;119:2204-13.

211. Hayden MR, Yang Y, Habibi J, et al. Pericytopathy: Oxidative stress and impaired cellular longevity in the pancreas and skeletal muscle in metabolic syndrome and type 2 diabetes. 0xid Med Cell Longev 2010;3:290-303.

212. Nishimura A. Are lectin positive spherical deposits detected in the molecular layer of the hippocampal formation related with neuronal apoptosis? J Med Invest 2010;57:183-90.

213. Daadi MM. In vitro assays for neural stem cell differentiation. Methods Mol Biol 2002;198:149-55.

214. Shihabuddin LS. Adult rodent spinal cord derived neural stem cells. Isolation and characterization. Methods Mol Biol 2002;198:67-77.

215. 0'Shea KS. Neural differentiation of embryonic stem cells. Methods Mol Biol 2002;198:3-14.

216. Miki T, Strom SC. Amnion-derived pluripotent/multipotent stem cells. Stem Cell Rev 2006;2:133-42.

217. Scintu F, Reali C, Pillai R, et al. Differentiation of human bone marrow stem cells into cells with a neural phenotype: diverse effects of two specific treatments. BMC Neurosci 2006;7:14.

218. Richards OC, Raines SM, Attie AD. The role of blood vessels, endothelial cells, and vascular pericytes in insulin secretion and peripheral insulin action. Endocr Rev 2010;31:343-63.

219. Djebaili M, Guo Q, Pettus EH, et al. The neurosteroids progesterone and allopregnanolone reduce cell death, gliosis, and functional deficits after traumatic brain injury in rats. $\mathrm{J}$ Neurotrauma 2005;22:106-18.

220. Check JH, Levin E, Bollendorf A, Locuniak J. Miscarriage in the first trimester according to the presence or absence of the progesterone-induced blocking factor at three to five weeks from conception in progesterone supplemented women. Clin Exp Obstet Gynecol 2005;32:13-4.

221. Borna S, Sahabi N. Progesterone for maintenance tocolytic therapy after threatened preterm labour: a randomised controlled trial. Aust $\mathrm{N} \mathrm{Z} \mathrm{J} \mathrm{Obstet}$ Gynaecol 2008;48:58-63.

222. Gray PB, Singh AB, Woodhouse LJ, et al. Dose-dependent effects of testosterone on sexual function, mood, and visuospatial cognition in older men. J Clin Endocrinol Metab 2005;90:3838-46. 
223. Coviello AD, Kaplan B, Lakshman KM, et al. Effects of graded doses of testosterone on erythropoiesis in healthy young and older men. J Clin Endocrinol Metab 2008;93:914-9.

224. Schram JH, Boerrigter PJ, The TY. Influence of two hormone replacement therapy regimens, oral oestradiol valerate and cyproterone acetate versus transder- mal oestradiol and oral dydrogesterone, on lipid metabolism. Maturitas 1995;22:121-30.

225. Rakyan VK, Down TA, Maslau S, et al. Human aging-associated DNA hypermethylation occurs preferentially at bivalent chromatin domains. Genome Res 2010;20:434-9.

226. Laurenzana A, Petruccelli LA, Pettersson
F, et al. Inhibition of DNA methyltransferase activates tumor necrosis factor alpha-induced monocytic differentiation in acute myeloid leukemia cells. Cancer Res 2009;69:55-64.

227. Bukovsky A. Ovarian stem cells and mammalian neo-oogenesis. Microsc Microanal 2008;14(Suppl 2):1474-5 